\title{
Downstream Amplification: A Possible Precursor to Major Freeze Events over Southeastern Brazil
}

\author{
T. N. Krishnamurti, Mukul Tewari, and D. R. Chakraborty \\ Department of Meteorology, The Florida State University, Tallahassee, Florida \\ Jose MARENGO \\ CPTEC/INPE Cachoeira Paulista, Brazil \\ Pedro L. Silva Dias \\ Department of Meteorology, University of Sao Paulo, Sao Paulo, Brazil \\ P. SATYAMURTY \\ CPTEC/INPE, Cachoeira Paulista, Brazil
}

(Manuscript received 12 February 1998, in final form 22 October 1998)

\begin{abstract}
Many frost events over southeastern Brazil are accompanied by a large-amplitude upper trough of the middle latitudes that extends well into the Tropics. This paper first illustrates that a mechanism of downstream amplification across the Pacific into South America is generally accompanied in these situations. This is manifested by troughs and ridges that propagate eastward. An analysis of these situations during frost events shows that these features of downstream amplification, illustrated on a Hovmöller $(x-t)$ plot, can be decomposed into a family of synoptic-scale waves that propagate eastward and a family of planetary-scale waves that acquire a quasi-stationary character during the freeze event. It is shown that a global model, at a resolution of $70 \mathrm{~km}$, can be used to predict these features on the decomposition of scales during freeze events. It became apparent from these features that the growth of the long stationary waves during the freeze events may be due to scale interaction among wave components. This paper discusses the nature of these scale interactions, calculated from the energetics in the wavenumber domain, for periods before, during, and after the freeze events. The salient results are that nonlinear barotropic-scale interactions are an important source for the maintenance of the downstream amplification; however, the baroclinic (in scale) contributions dominate through the life cycle of the downstream amplitude where the large-amplitude troughs are indeed accompanied by baroclinic features. Finally, it is shown that a very high resolution regional spectral model can be used to handle the local aspects of the freeze events. This study offers the possibility for designing prediction experiments on the medium-range timescales for the forecast of these frost events.
\end{abstract}

\section{Introduction}

Factors controlling freeze events over subtropical and tropical latitudes during the winter season generally are accompanied by a large-amplitude trough of the middlelatitude westerlies. The tropical extension (or penetration) of such a large-amplitude trough appears, clearly, to be associated with synoptic- to planetary-scale events. The frost over southeastern Brazil is known to have devastating effects on the coffee crops and a prediction of such events is of considerable interest to the agri-

Corresponding author address: Dr. T. N. Krishnamurti, Dept. of Meteorology 3034, The Florida State University, 430 Love Building, Tallahassee, FL 32306. cultural community. The theme of this paper is to present four interconnected areas that are relevant to the heavy frost over southeastern Brazil. We first take nine examples of recent frosts and show that the large-amplitude 500-hPa trough over Brazil had very interesting antecedents. We show that these antecedents are composed of wave trains exhibiting downstream amplification. These wave trains arrive over South America all the way from across the Pacific Ocean. Such wave trains are known to traverse across the Pacific at a frequency of roughly one passage every 3 weeks during the winter season. We next decompose these waves into their scales. Here we show that the 500-hPa geometry of the downstream amplification is composed of quasi-stationary long waves and faster eastward-moving transients. We next ask the question: do these waves interact? We 
show that indeed there is an energy exchange from the quasi-stationary long wave toward the shorter waves. This contributes to the buildup of the large-amplitude middle-latitude trough over South America leading to the frost over southern Brazil. Finally we make use of this above knowledge toward the design of a forecast experiment that enables us to show one case of a successful forecast of a freeze event. In the paper we illustrate a phenomenon of downstream amplification that precedes most recent heavy frost events. As a word of caution to the reader, it should be emphasized that the downstream amplification, we illustrated here, may only be one of several important factors during intense frosts over southeast Brazil. In this paper, we shall show that an interesting grouping of short and long waves describes the geometry of this downstream amplification in Hovmöller diagrams ( $x-t$ diagrams of the $500-\mathrm{mb}$ geopotential field). Furthermore, we show that these large-amplitude troughs of these freeze events undergo some very interesting scale interactions (kinetic and available potential energy exchanges among waves). We also address the issue of prediction of such events on the medium-range timescale, using a high-resolution global model. The prediction of downstream amplification and the prediction of below freezing surface air temperatures are some issues of interest here. Schultz et al. (1998) have made a detailed observational study of cold surges over North America. They address the southward surges of cold air from the Canadian Arctic toward Central America. In their study, they have distinguished between short and long duration surges and multiple surges within individual cold events. Our study over the Southern Hemisphere explores these issues using scale decomposition and scale interaction issues. Our study closely parallels the recent papers of Shultz et al. (1998) and Colle and Mass (1995). However, this study has generally ignored the topographic controls for these cold surges/frosts. Finally, we have demonstrated that a high-resolution regional spectral model can be used for the detailed prediction of frosts over southeastern Brazil.

\section{A case study of an intense freeze event over southeastern Brazil during June 1994}

\section{a. Synoptic-scale features}

According to Marengo et al. (1997a,b) during the 1994 May-August winter season, as many as 14 cold waves, some of them associated with frost and snow over southern Brazil, were noted. Some of these cold waves moved equatorward and reached southern Amazonia, producing sharp reductions of temperature in southern Amazonia, while the cooling was not so strong over central Amazonia. In this section we will describe the evolution of minimum temperatures in Amazonia and southern Brazil during the cooling of the June 1994 episode, using the National Center for Atmospheric Re-

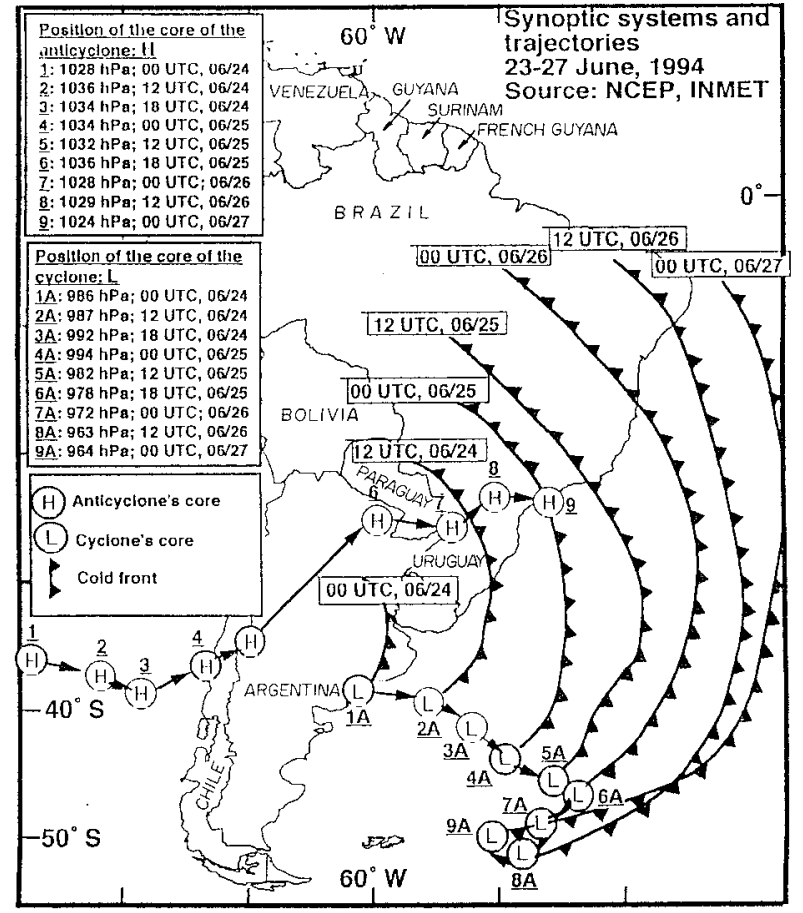

FIG. 1. Passage of a cold front during the freeze event covering the period of 0000 UTC 24 Jun through 0000 UTC 27 Jun 1994. The positions of the surface lows and highs are denoted by the letters L and $\mathrm{H}$.

search-National Centers for Environmental Prediction 40-yr Reanalysis, (Kalnay et al. 1996) as well as weather information from the observational networks from Brazil.

On the third week of June, the upper-atmospheric flow over the South Pacific showed a southwest-northeast orientation of the subtropical jet over South America, this was associated with a deep trough along the coast of southern Brazil and Argentina, which favored the movement of frontal systems and anticyclones into lower latitudes. This was especially noticeable on 23 June, some 3 days before the coldest date, and to a lesser degree on 26 June (the coldest day). On 23 June, a pair of ridge-trough systems were detected over the central and eastern Pacific, traveling eastward, with a deep trough over the coast of southern Brazil and Argentina. On this day, the trough showed a strong confluence of flow over northern Argentina from the southwest and also from the northwest. On 26 June, those systems moved to the east, with one ridge parallel to the coast of Chile and the trough extended into southern Brazil from north-central Argentina.

From 1200 to 1800 UTC 25 June (Fig. 1), the anticyclone moved along the eastern flank of the Andes with an intensity of $1036 \mathrm{hPa}$, while the cyclone over the South Atlantic reached $982 \mathrm{hPa}$ and the cold front was located over Rio de Janeiro. On the coldest day, 26 June, the maps at 0000 and 1200 UTC showed that the 
anticyclone was located over southern Brazil. The anticyclone extended into southwestern Amazonia and its intensity was somewhat reduced $(1028 \mathrm{hPa})$. The cold front was now over southeastern Brazil, reaching eastern Brazil some $12 \mathrm{~h}$ later. On this day, temperatures of less than $0^{\circ} \mathrm{C}$ were recorded at Londrina and $\mathrm{Foz}$ de Iguacu in southeastern Brazil (Marengo 1997a,b). At 0000 UTC 27 June, the anticyclone weakened (1024 hPa) and had moved to the east. In this period, the cyclone intensified reaching $964 \mathrm{hPa}(22 \mathrm{hPa}$ lower than on 24 June) and located at $50^{\circ} \mathrm{S}, 40^{\circ} \mathrm{W}$.

Figure 1 shows the mean position of the core of the cold anticyclone and the core of the cyclone over Argentina south of $40^{\circ} \mathrm{S}$; also shown are the positions of the cold front for 0000 and 1200 UTC, from 24 to 27 June 1994. At 0000 UTC 24 June, the anticyclone over the Pacific moved to the east reaching $85^{\circ} \mathrm{W}$, while at 1200 UTC on the same day, the anticyclone intensified and was located closer to the coast of South America. The trough evolved into a cold front that extended over the extreme southern Brazil, and the cyclone was more intense and was now located over $42^{\circ} \mathrm{S}, 53^{\circ} \mathrm{W}$.

Starting at 1200 UTC on June 24 , the anticyclone approached the Andes, and the curvature of the isobars south of $40^{\circ} \mathrm{S}$ indicated that the cold air was trying to cross the Andes where elevation is lower. This was observed from 0000 UTC 24 June through 0600 UTC 25 June (Marengo 1997a). During this period, the front was located over southeastern Brazil, and the cyclone was located over the South Atlantic where it had become more intense and had displaced eastward. In reference to anticyclones passing the Andes, Lichtenstein (1989) indicated that cold air that enters the continent from the southwest, where elevation is more than $2000 \mathrm{~m}$ above sea level, cannot cross the Andes and is forced to turn around the obstacle exhibiting an increase in its anticyclonic curvature. This can be observed south of $45^{\circ} \mathrm{S}$ in Figs. 2a,b.

The 26 June event, as well as other events of the same winter (9-10 July and 10 August 1994), were characterized by the presence of an anticyclonic perturbation off the coast of Chile that entered South America and moved across the Andes south of $45^{\circ} \mathrm{S}$, where the elevation is relatively low. The northward displacement of the anticyclone followed a meridional continental track until it reached around $20^{\circ}-30^{\circ} \mathrm{S}$; thereafter it moved eastward toward the Atlantic. This is a typical feature in these three cases, as well as in other cases documented in the literature. The difference could lie in the intensity of the northward flow along the eastern flank of the Andes, in the intensity of the high pressure, and in the latitudinal positions of both the entrance of the anticyclone into South America and its most equatorial position during the coldest days. The area affected by the anticyclone also varies, especially in the southeast flank.

\section{b. Planetary-scale aspects}

Figures 3a-c illustrate, for the June 1994 case, a Hovmöller diagram of 500-mb geopotential heights (merid-
00 UTC; 24/JUN/94

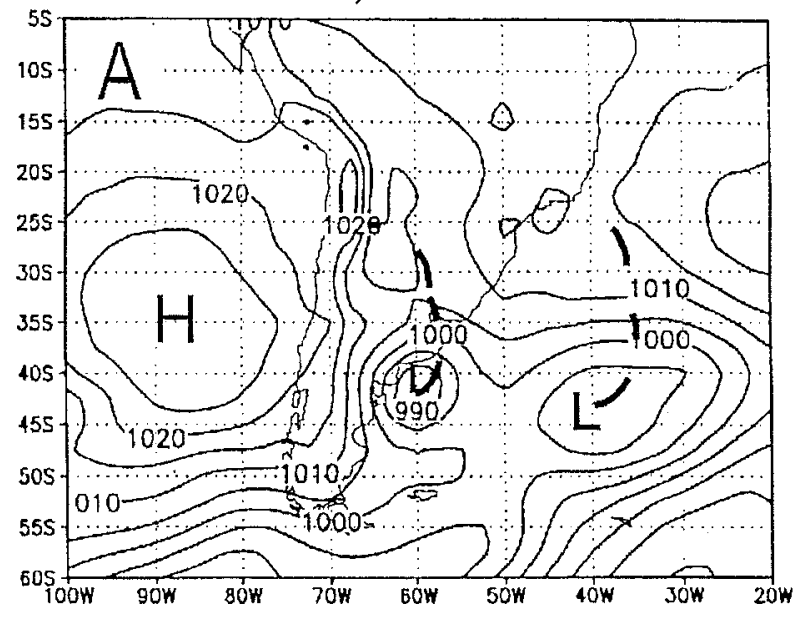

00 UTC; 26/JUN/94

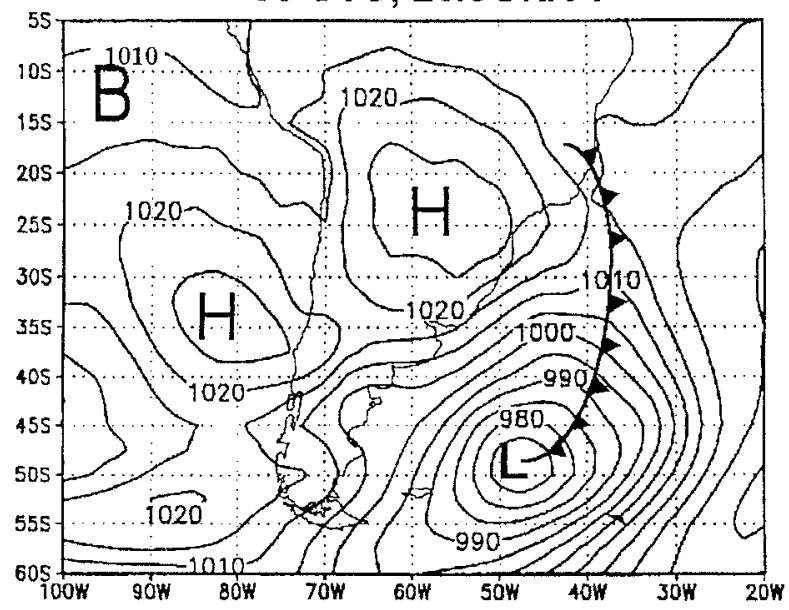

FIG. 2. (a), (b) Synoptic situations during a freeze event at 0000 UTC 24 and 26 Jun 1994. Sea level isobars (interval, $5 \mathrm{mb}$ ).

ionally averaged between $25^{\circ}$ and $45^{\circ} \mathrm{S}$ ) and its decomposition with its long- (zonal wavenumbers 1-3) and short- (zonal wavenumbers 4-10) wave components, respectively. Here we take the 500-hPa heights around the latitude circles between $25^{\circ}$ and $45^{\circ} \mathrm{S}$ and average them in the south to north direction; thus, we have one dataset of averaged geopotential heights from west to east around the globe. This dataset is subjected to a zonal harmonic analysis. The variances and the phases of these computed individual waves show that in general the long waves composed of zonal wavenumbers 1,2 , and 3 are quasi-stationary and the higher wavenumbers 4-10 are eastward propagating. It is this grouping that we illustrate in this paper. The striking feature in Fig. $3 \mathrm{a}$ is the downstream amplification that encircles the globe in roughly 15 days, suggesting a group velocity of roughly $24^{\circ}$ long day ${ }^{-1}$. We use the phrase downstream amplification in the following context. It means 

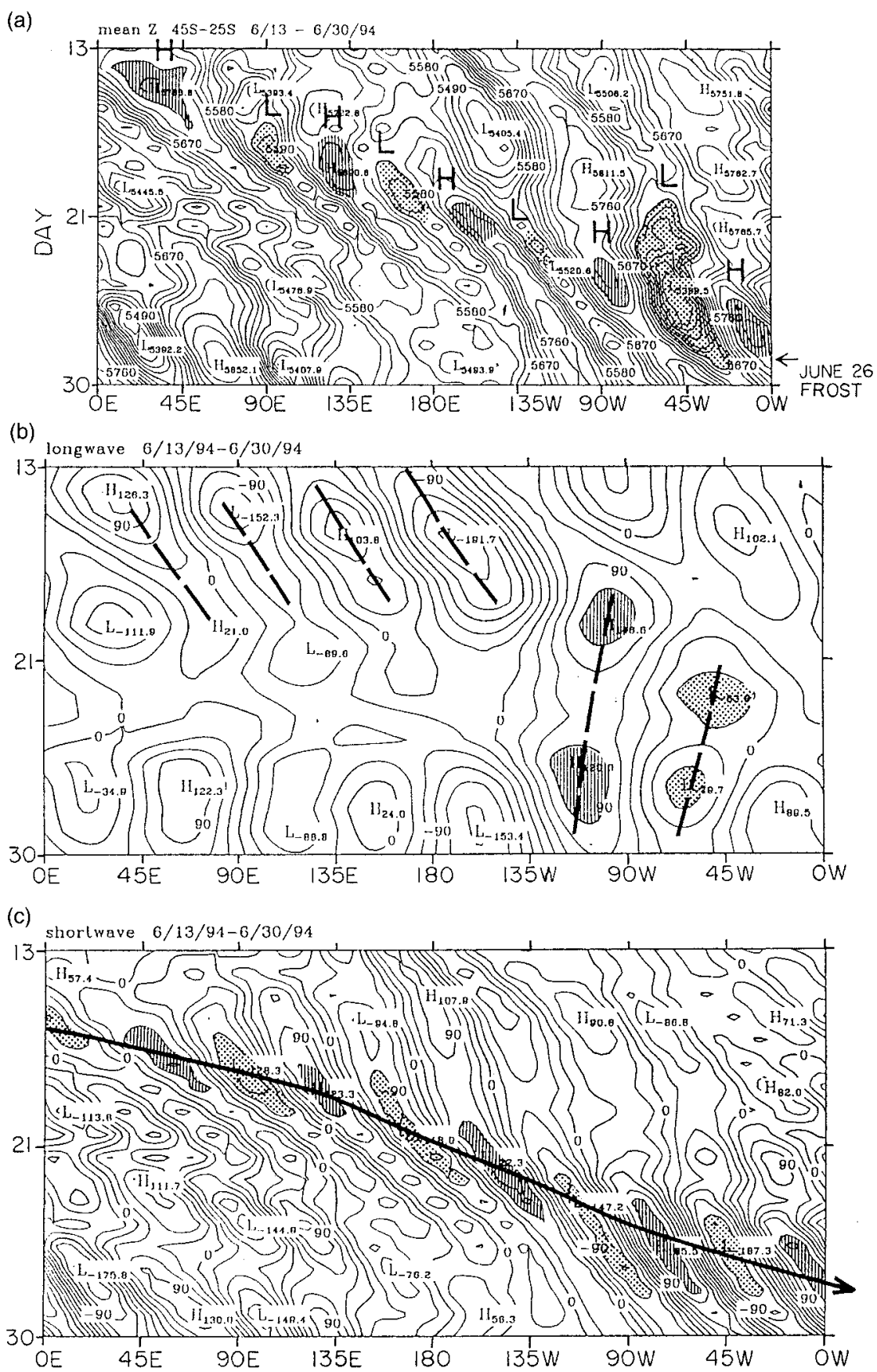

FIG. 3. (a), (b), (c) Hovmöller diagram of 500-mb geopotential height and its decomposition with its long- and short-wave components, respectively.

the formation of a succession of lows and highs in the Hovmöller diagrams in the manner of Fig. 3a. Most of the time, such successions of lows and highs are simply not seen, meaning that there is no downstream amplification. The very presence of a low-high-low family on the Hovmöller diagram implies amplification. The phase velocity of the individual trough and ridge systems at the $500-\mathrm{mb}$ level are of the order of $5^{\circ}$ long day $^{-1}$. Of particular interest, is the region around $60^{\circ} \mathrm{W}$, which is straddled by a trough to the east and a ridge to the west. In this region, the height gradient suggests a sustained southerly flow over an extended period of several days, which leads to a sustained freeze period. Figure $3 b$ illustrates this zonal time history of the long wave during this 18-day period. We note here that the long waves were slowly progressing eastward; they 


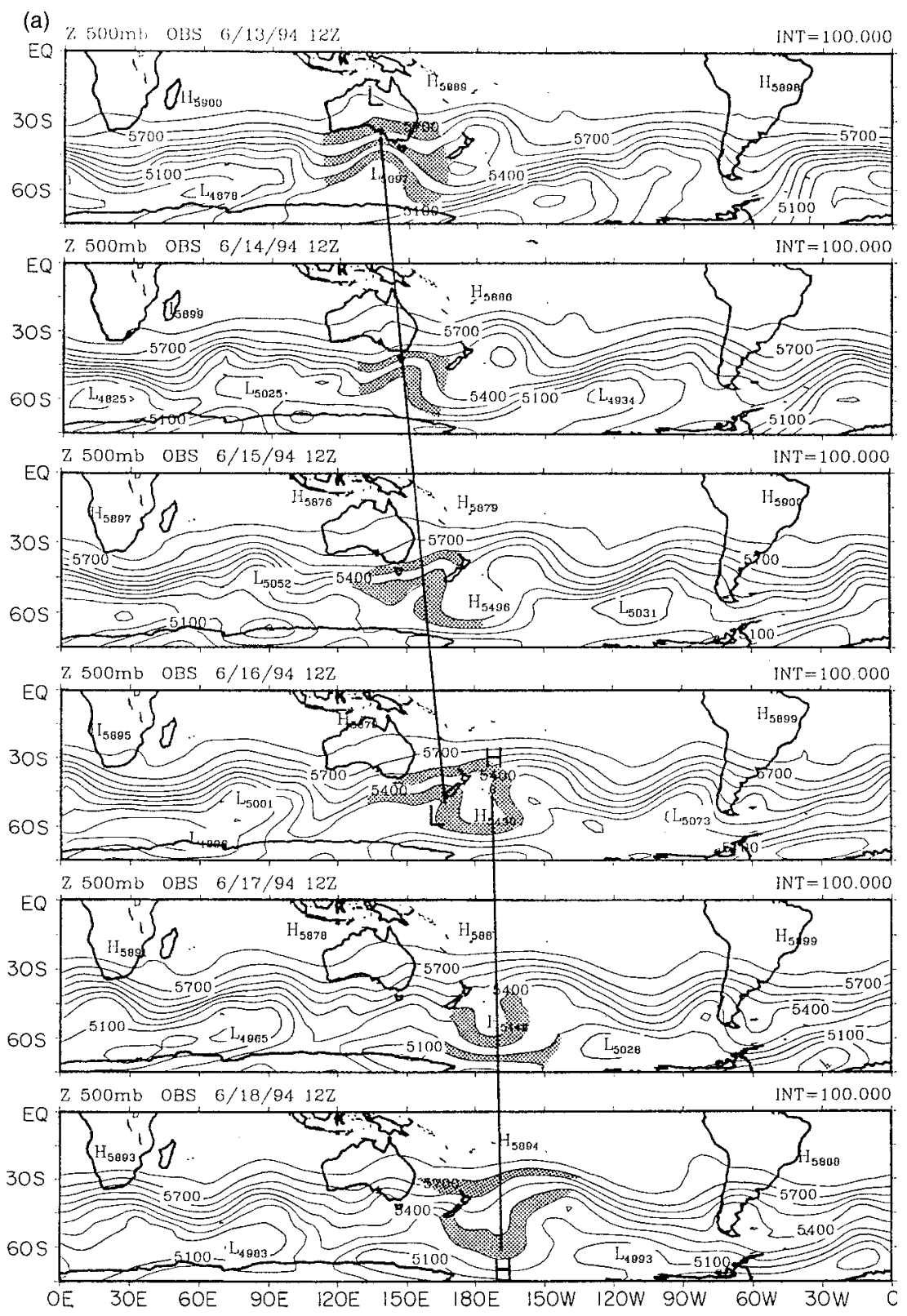

FIG. 4. (a), (b), (c) A sequence of 500-mb charts starting at 1200 UTC 13 Jun 1994. Contour interval is $100 \mathrm{~m}$. These charts emphasize the successive development

slowed and slowly retrogressed starting some 5 days prior to the severe frost of 26 June 1994. The shorter waves during this entire period established an eastward motion; they appear to have much slower phase propagation during the period of the frost. The sustained height gradient for the southerly (geostrophic) flow noted in Fig. 3a appears to be largely contributed by the shorter waves shown in Fig. 3c. The reasons for the abrupt shift of the behavior of long waves is not clear. It appears from this breakdown of the short and long waves that some interesting scale interactions were oc- curring; these were quite revealing on the quasi stationarity of these large-amplitude systems that eventually led to the severity of the frost. We shall address these issues in section 4. In section 3, Fig. 8j is based on a composite of all nine cases of severe frosts that are illustrated in the following pages. This figure is a composite Hovmöller diagram based on averaging of the $500-\mathrm{mb}$ geopotential heights from $25^{\circ}$ to $45^{\circ} \mathrm{S}$. It shows the downstream amplification, that is, alternating lows and highs, similar to what is seen for a single case.

A sequence of $500-\mathrm{mb}$ charts covering the period 13 
(b)
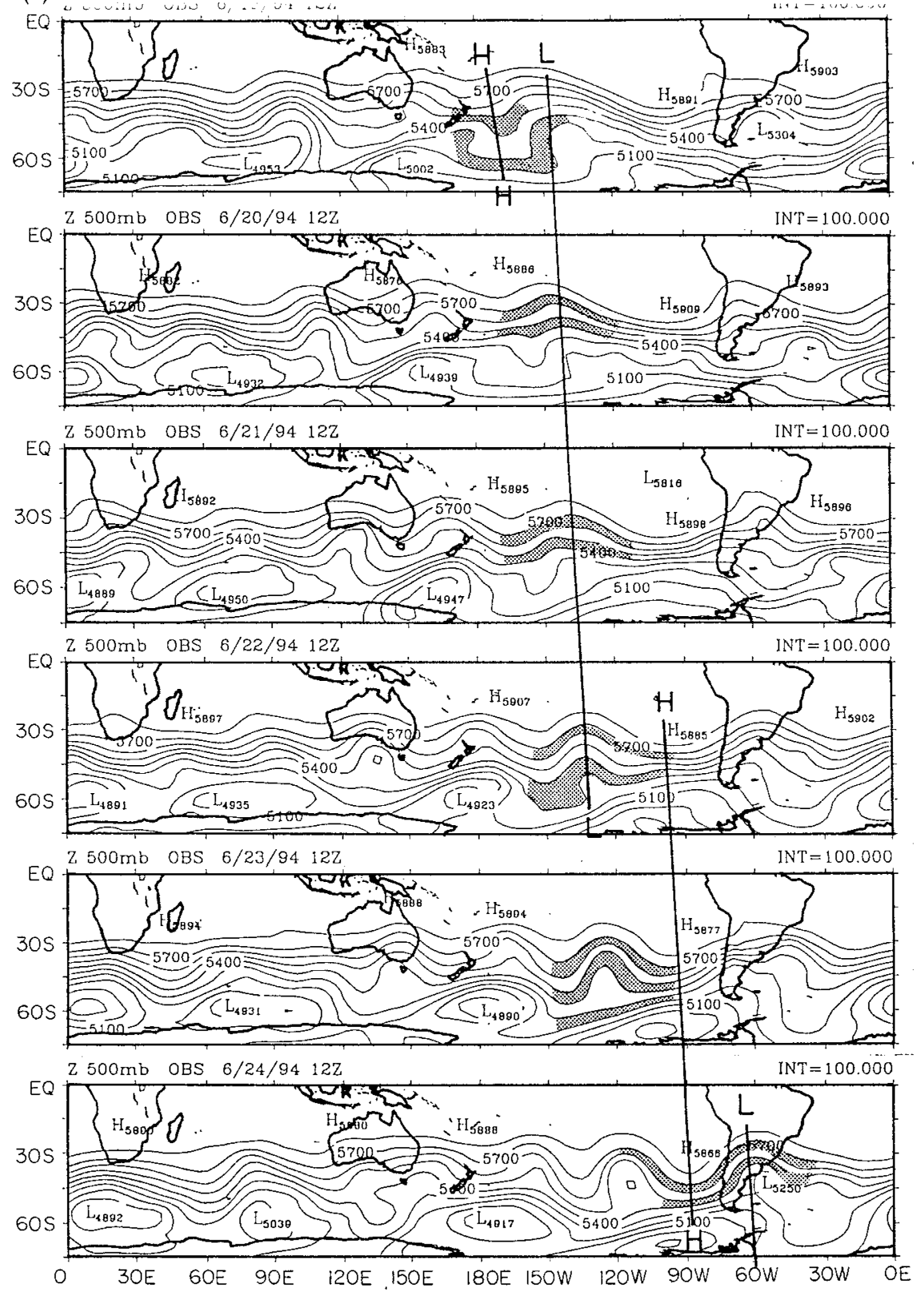

FIG. 4. (Continued) and motion of trough-ridge systems over the southern Pacific Ocean, illustrating the downstream amplification.

to 30 June 1994 is illustrated in Figs. 4a-c. Here we see an initial trough south of Australia making its eastward passage during the first 4 days. The downstream ridge is discernible, during a 4-day period, which is followed by the amplification and eastward passage of a South Pacific trough during the next 5 days. This sequence follows through a downstream amplification of a ridge for another 4 days prior to the major event of a trough amplification over South America. This last system is the one of interest in the context of the major freeze over southeastern Brazil around 26 June. The vertical lines connect in time illustrating the basic centers of the downstream amplification. A blocking high temporarily appears northeast of New Zealand. That blocking feature is not central to what is being emphasized here. The high and the low pressure systems of this block do unravel in time as distinct components of the downstream amplification. There were two trough passages related to the cold event across South America on 16-23 June 1994. The significance and the relationships of such multiple events are not studied in this paper. It is conceivable that the termination of the freeze 

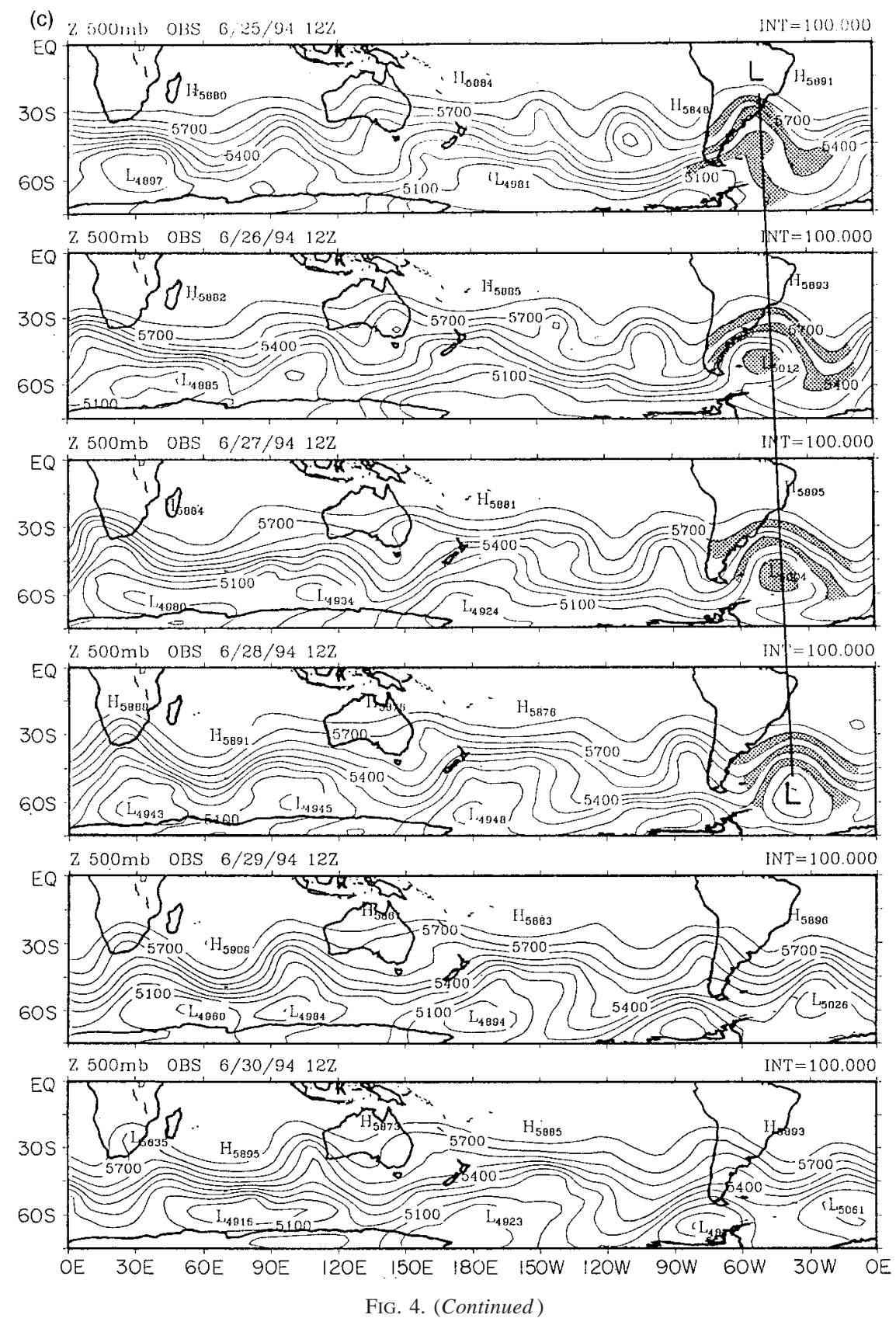

event of 25-26 June 1994 was related to the arrival of the ridge (located near $120^{\circ} \mathrm{W}$ ).

\section{c. Numerical weather prediction of the freeze event}

We have used the current Florida State University global spectral model, described in Krishnamurti et al. (1991), to predict the freeze event of June 1994. An outline of the model is as follows.

The model has independent variables $\lambda, \phi, \sigma, t$. The dependent variables are vorticity, divergence, temperature, and a moisture variable (dewpoint depression, $T$
$-T_{d}$ ). The model has $512 \times 256$ Gaussian transform grid coordinates corresponding to a triangular spectral truncation T-170 in the horizontal. In the vertical, it has 14 layers between 50 and $1000 \mathrm{mb}$. Model variables are staggered in the vertical using Charney-Phillips vertical discretization. Vorticity, divergence, and geopotential are located at the layer interfaces while temperatures, specific humidity, and vertical velocity are assigned at the center of the layers. The vertical grid has higher resolution in the upper troposphere and in the planetary boundary layer. The surface topography is based on envelope orography (Wallace et al. 1983). The model has 


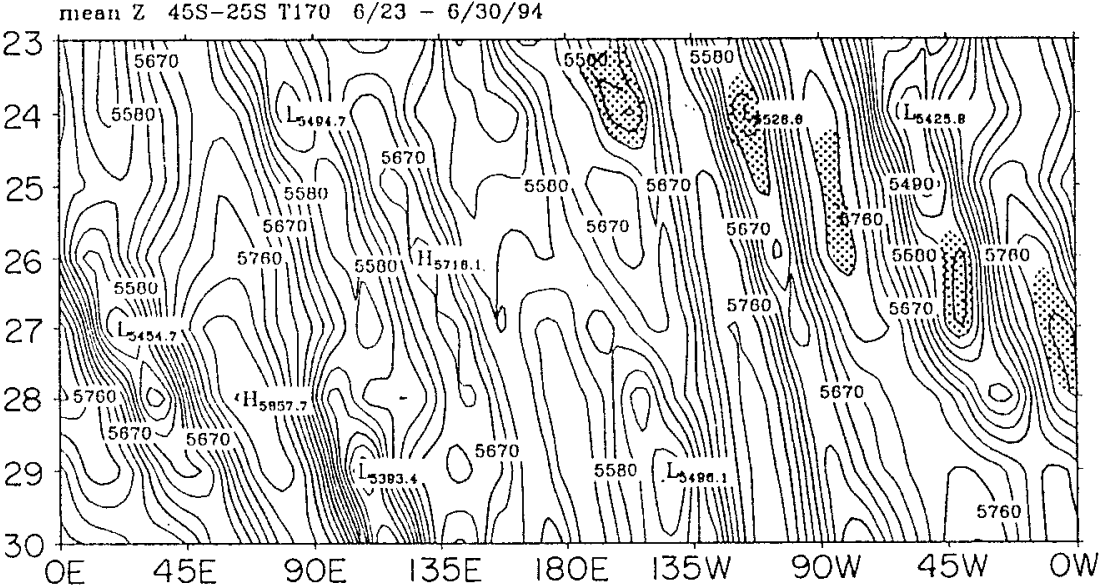

FIG. 5. Predicted 500-mb height field shown on a Hovmöller $(x-t)$ diagram covering the period 23-30 Jun 1994.

deep convection based on a modified Kuo cumulus parameterization scheme (Krishnamurti et al. 1983), where moistening and heating parameters are statistically improved over the conventional Kuo-type scheme. The model includes shallow convection (Tiedke 1984), dry convection, and large-scale condensation (Kanamitsu 1975). We also account for the evaporation of falling precipitation. The surface fluxes of heat, moisture, and momentum are calculated using the surface similarity theory (Businger and Wyngard 1971). For low speeds $\left(\leq 5 \mathrm{~m} \mathrm{~s}^{-1}\right)$ moisture fluxes are modified following Beljaars and Miller (1990). The vertical distribution of fluxes in the free atmosphere are based on stability (Richardson number) dependent exchange coefficient (Louis 1979). It also includes a fourth-order horizontal diffusion scheme (Kanamitsu et al. 1983). The long- and shortwave radiative fluxes are based on a band model that incorporates the radiative effects of water vapor, carbon dioxide, ozone, and clouds (Harshvardan and Corsetti 1984; Lacis and Hansen 1974). Parameterization of low, medium, and high clouds for radiative transfer calculation are based on the definition of threshold relative humidity for three different layers. Fractional areas of various cloud distribution configurations in the vertical are based on a random overlap cloud model. The surface temperatures are prescribed for the oceans. Over the land surface energy balance coupled to similarity theory determines the surface temperature including its diurnal cycle (Krishnamurti et al. 1991). The initialization of the model is based on physical initialization wherein the moisture field, heat sources, and sinks and divergence fields are initialized consistent with observed outgoing long wave radiation and rain rates.

One of the challenges of a medium-range forecast is to asses how well such a global model handles the wave train and the downstream amplification that precedes the freeze event. In that context, the model performed exceedingly well in predicting these events. Figure 5 illustrates the Hovmöller $(x-t)$ diagrams of the predicted 500 -mb geopotential height, averaged between $25^{\circ}$ and $45^{\circ} \mathrm{S}$ latitude. The downstream amplification related to the large-amplitude trough over the Brazilian longitude is reasonably predicted. The predicted isotherms of surface air on day 3 (which includes 1 day of physical initialization) of the forecast are shown in Fig. 6. The

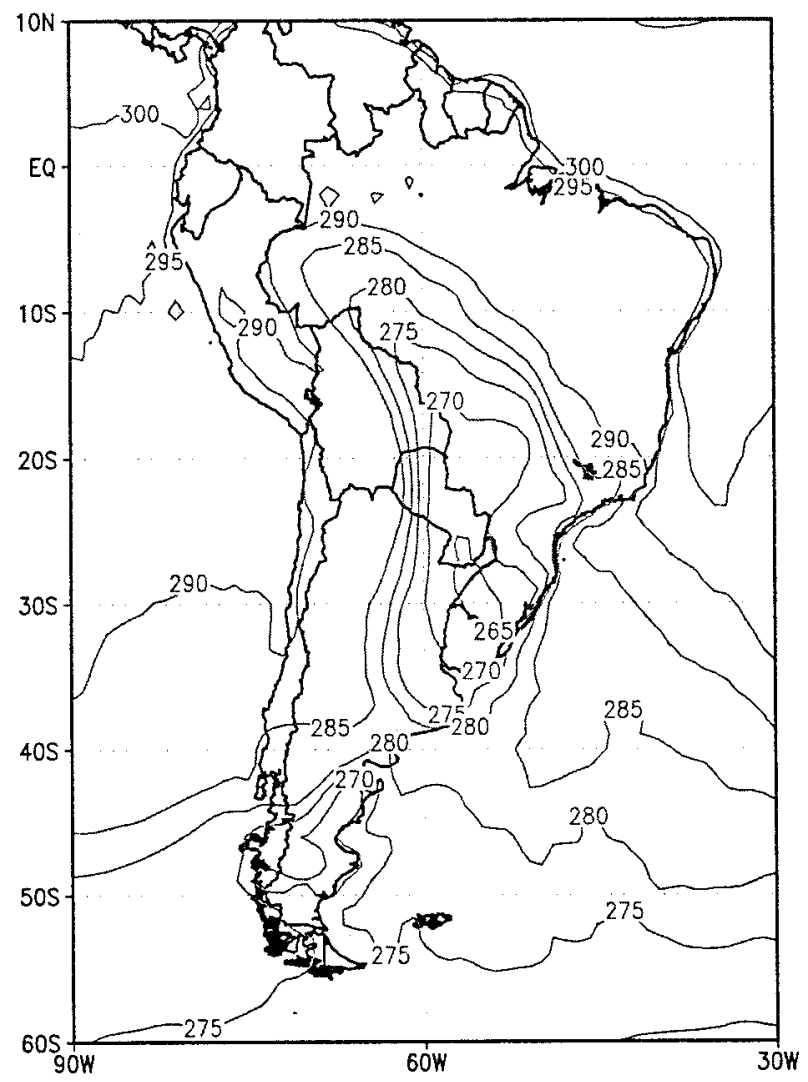

FIG. 6. Predicted temperature field at $1000 \mathrm{mb}$ on 26 Jun 1994 (day 3 of the forecast). 
results were projected on the $1000-\mathrm{mb}$ surface prior to showing the verification. Maps at the $\sigma=1$ surface are never that interesting, since they reflect mostly the mountains. The geometry of the $1000-\mathrm{mb}$ contours are quite similar to those of sea level pressure, and these are very interesting. This was the day of frost over southeastern Brazil (longitude $45^{\circ} \mathrm{W}$ ). The model brings the $0^{\circ} \mathrm{C}$ isotherm of the surface air temperature close to this region of frost. Clearly, the global model with a resolution T170, that is roughly $70 \mathrm{~km}$ for the horizontal separation of the transforming grid, fails to capture the detailed prediction of frost.

\section{d. High-resolution regional forecast}

A regional spectral model was recently developed by Cocke (1998) for high-resolution forecasts of weather phenomena. This is a one-way nested high resolution that utilizes physical initialization and lateral boundary conditions from the global model. This model is ideally suited for higher-resolution frost forecasts. This regional model utilized a horizontal resolution of roughly $50 \mathrm{~km}$ and 15 vertical levels between the earth's surface and the $30-\mathrm{hPa}$ surface. We shall illustrate the results of forecasts starting at 1200 UTC 24 June 1994. The major frost was observed on 26 June 1994. Thus a high-resolution two-day forecast is of interest here. Figures 7a,b illustrate the surface ( $\sigma$ $=1$ surface) air temperature at hours 24 and 48 of forecasts. The coloring scheme clearly shows the northward advance of subfreezing temperatures by hour 48 over the region of southeastern Brazil. Thus it appears that a combination of the global and highresolution regional spectral models can be effectively used to predict these freeze events. The prediction of the wave train (the Hovmöller downstream amplification) is suggested as a prerequisite prior to a regional high-resolution forecast of the local aspects of the freeze. We have not examined the topographic influences of the trapping of cold air in all of the nine cases. The only case where this was possible was that where we had examined multiple levels of data for all variables. This was the 26 June 1994 episode of freeze. What we found was somewhat contrary to the common notion of orography-trapped cold air drawing from the southern latitudes. This is clearly apparent in Fig. 7b. Here we note an axis of cold air over the mountain chain that simple reflects the cold air temperature over the mountain on the $\sigma=1$ surface. The frost over southeastern Brazil was associated with an intense upper trough located close to $50^{\circ} \mathrm{W}$ (Fig. 7b). Southerlies to the west of this trough brought very cold air southward. This southerly flow is located quite far to the
TABLE 1. Surge events used in the composite [based on the National Aeronautics and Space Administration/Goddard Earth Observing System reanalysis, Cornejo et al. (1997), and NCEP reanalysis (Marengo et al. 1997a)].

\begin{tabular}{|c|c|c|}
\hline \multicolumn{3}{|l|}{ Strong } \\
\hline 8 Jun 1985 & $22 \mathrm{Jul} 1986$ & 26 May 1988 \\
\hline 13 Jul 1988 & $26 \mathrm{Jul} 1988$ & 27 May 1989 \\
\hline 7 Jul 1989 & 19 May 1990 & 22 May 1990 \\
\hline 26 Jun 1994 & $10 \mathrm{Jul} 1994$ & 9 Aug 1994 \\
\hline \multicolumn{3}{|l|}{ Moderate } \\
\hline 19 Jun 1985 & 14 May 1986 & 22 May 1986 \\
\hline 2 Jul 1986 & 7 Jul 1986 & 10 Jun 1987 \\
\hline 18 May 1988 & 13 May 1990 & 16 Jun 1990 \\
\hline 22 Jun 1990 & 20 May 1991 & 9 Jun 1991 \\
\hline 4 Jul 1991 & 12 Jul 1991 & 28 May 1993 \\
\hline 19 Jul 1993 & & \\
\hline
\end{tabular}

east of the Andes Mountains. There is no clear evidence of an orography-trapped southerly flow. The orographic trapping of cold air is probably not obvious at this point because it is late in the case. The surge has already moved into lower latitudes (Fig. 6), and temperature modifications are now occurring along the Andes (possibly downslope warming). This is analogous to along the Rockies, where Texas gets a cold surge initially, then the cold air advects eastward and Florida gets the freeze a couple of days later while Texas starts warming up. This feature, most likely, is related to the baroclinic amplification of the system well to the east of the mountains.

\section{Other cases of severe frost over southeastern Brazil during a recent decade}

Table 1 lists 12 cases of severe frost that occurred over this region since 1985. This tabulation makes use of strong (S) and moderate (M) cold surges. These episodes were classified by Cornejo et al. (1997, manuscript submitted to Int. J. Climatol.) according to the 850-hPa temperature drops in an area located near coffee growing zones in southeastern Brazil. During the cold outbreaks the surface air temperature exhibits a drop over several days; the criteria classifies the events depending on the total temperature drop in the episode. The $\mathrm{S}$ cases had such a drop between $8^{\circ}$ and $11^{\circ} \mathrm{C}$, while that value during the $\mathrm{M}$ events was between $3^{\circ}$ and $5^{\circ} \mathrm{C}$.

The events listed as strong cold events produced severe damage to the coffee-growing areas of southern and southeastern Brazil. The events of June and July 

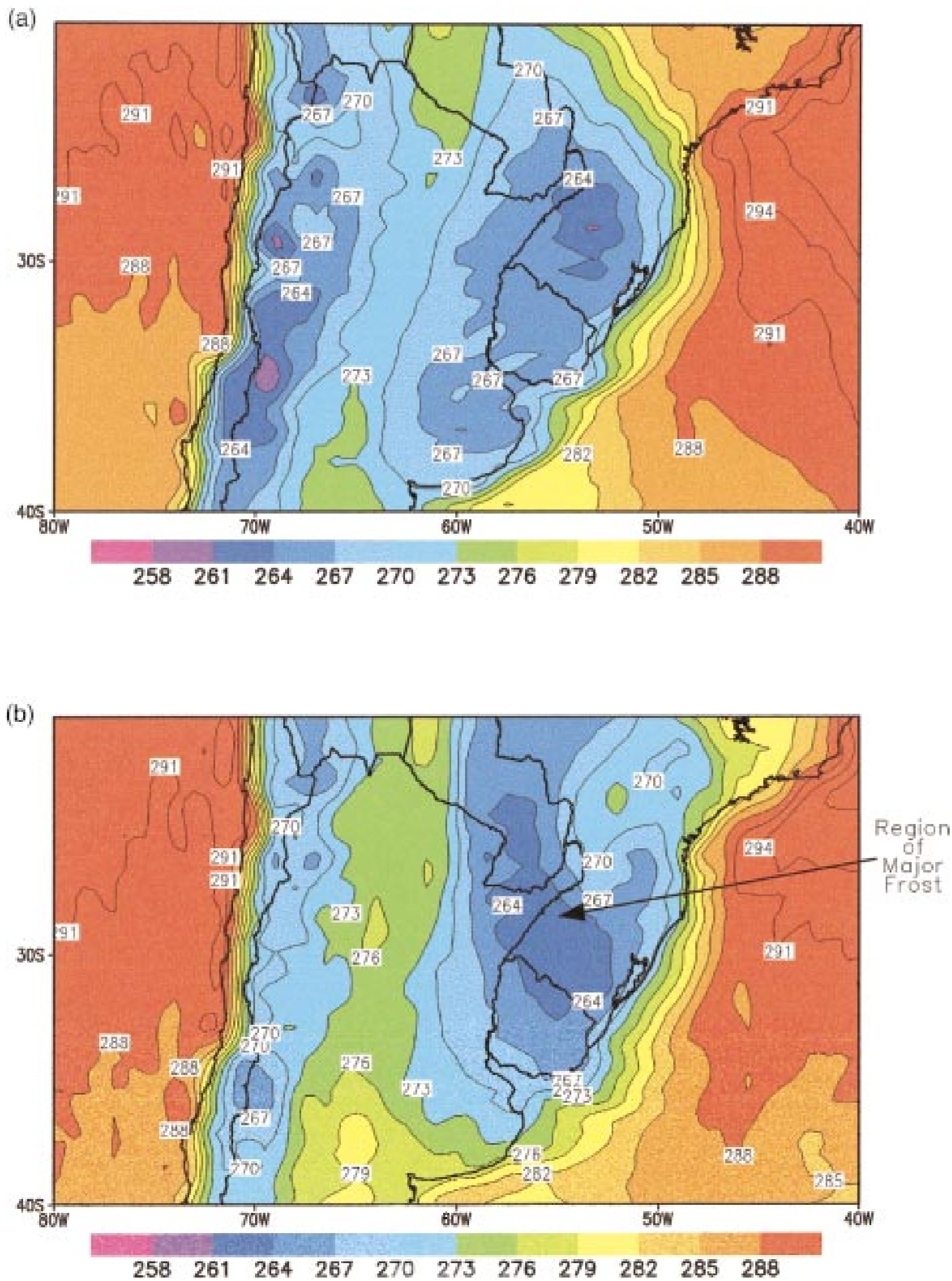

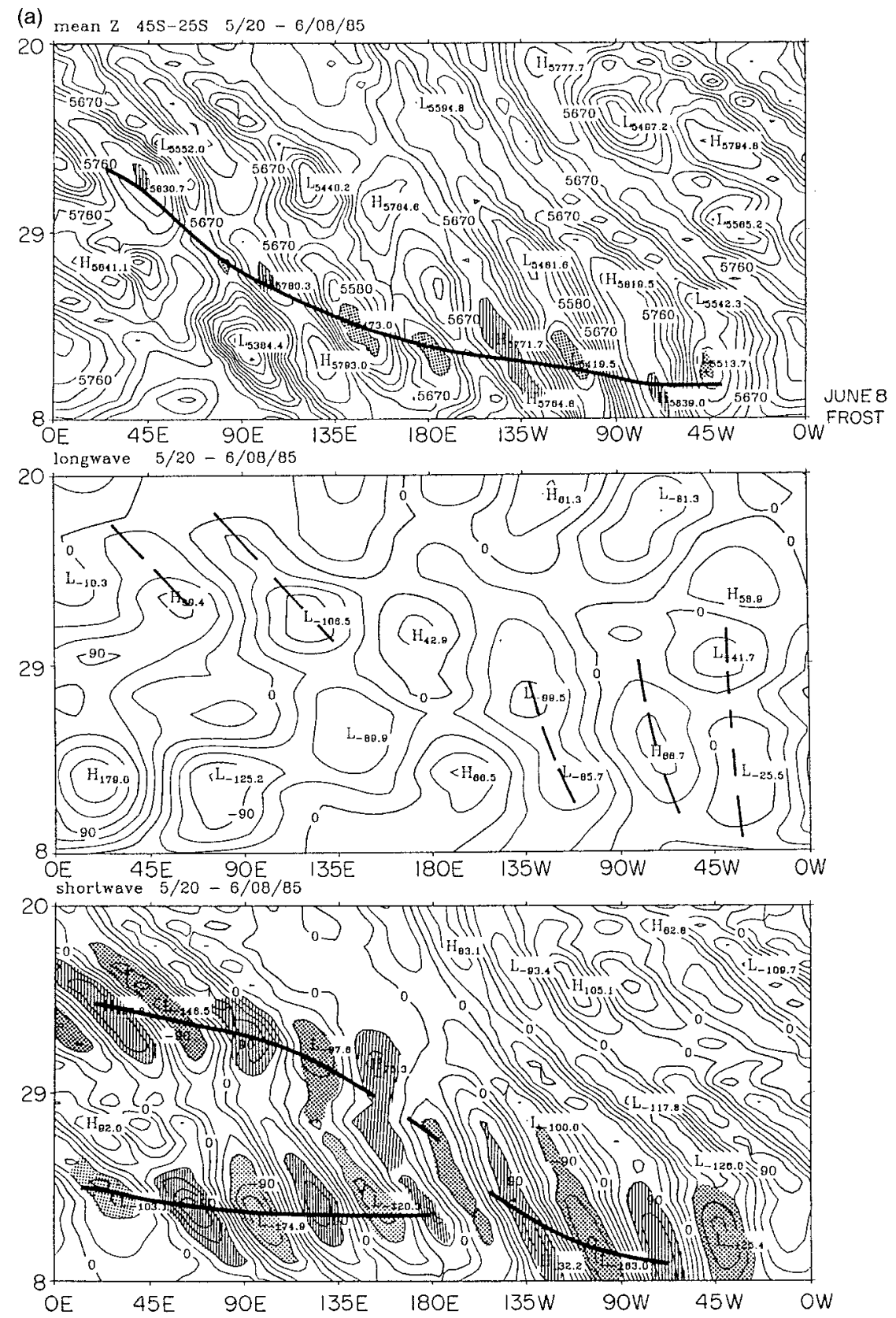

FIG. 8. (a)-(j) A sequence of Hovmöller $(x-t)$ diagrams illustrating downstream amplification where the shaded areas emphasize the presence of a downstream amplifying system. (top) 500$\mathrm{mb}$ heights; intervals, $10 \mathrm{~m}$. The heavy black line emphasizes downstream amplification with the alternating lows and highs shaded. (middle) Same as the top panel except for the long waves.

1994 caused a sharp drop in coffee production (almost $80 \%$ losses in the southern states of Brazil) and dramatic increases in coffee prices (Marengo 1997a). No severe events affecting the coffee crops over this region were noted during 1995 and 1996. In the present study, we are only addressing the cases of severe frost.

Figures 8a-i illustrate nine three-panel charts using the Hovmöller representation for the geopotential heights; the long- and short-wave breakdown for these nine cases are also shown. It is apparent from a quick inspection of these Hovmöller charts of the geopotential heights of $500 \mathrm{mb}$, between $25^{\circ}$ and $45^{\circ} \mathrm{S}$, that a wave train exhibiting a downstream amplification is indeed present in almost all cases. Nine cases of downstream amplification are discussed in this section. The very presence of alternating lows and highs in a Hovmöller 
(b)

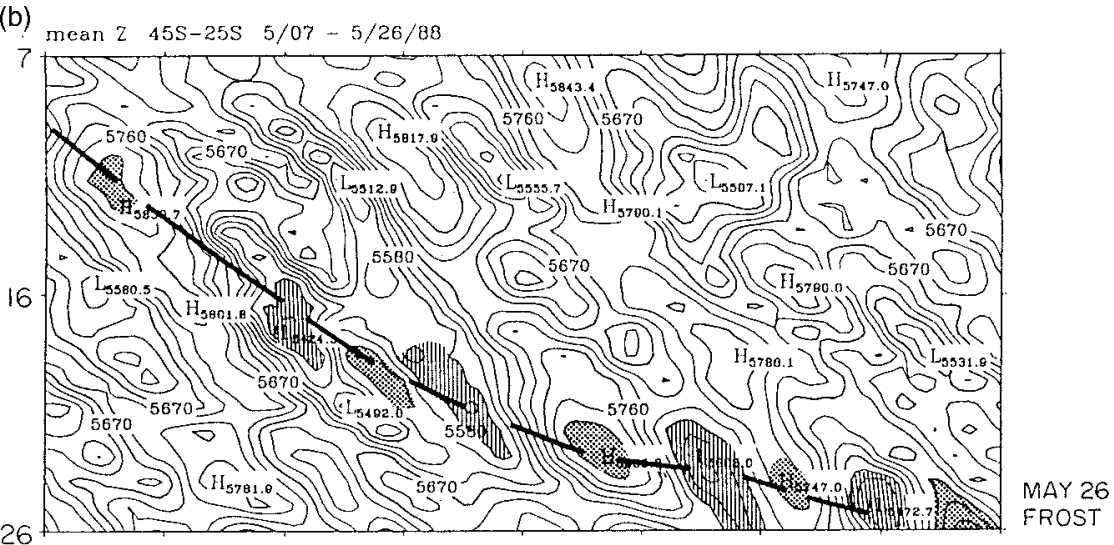

longwave $5 / 07-5 / 26 / 88$
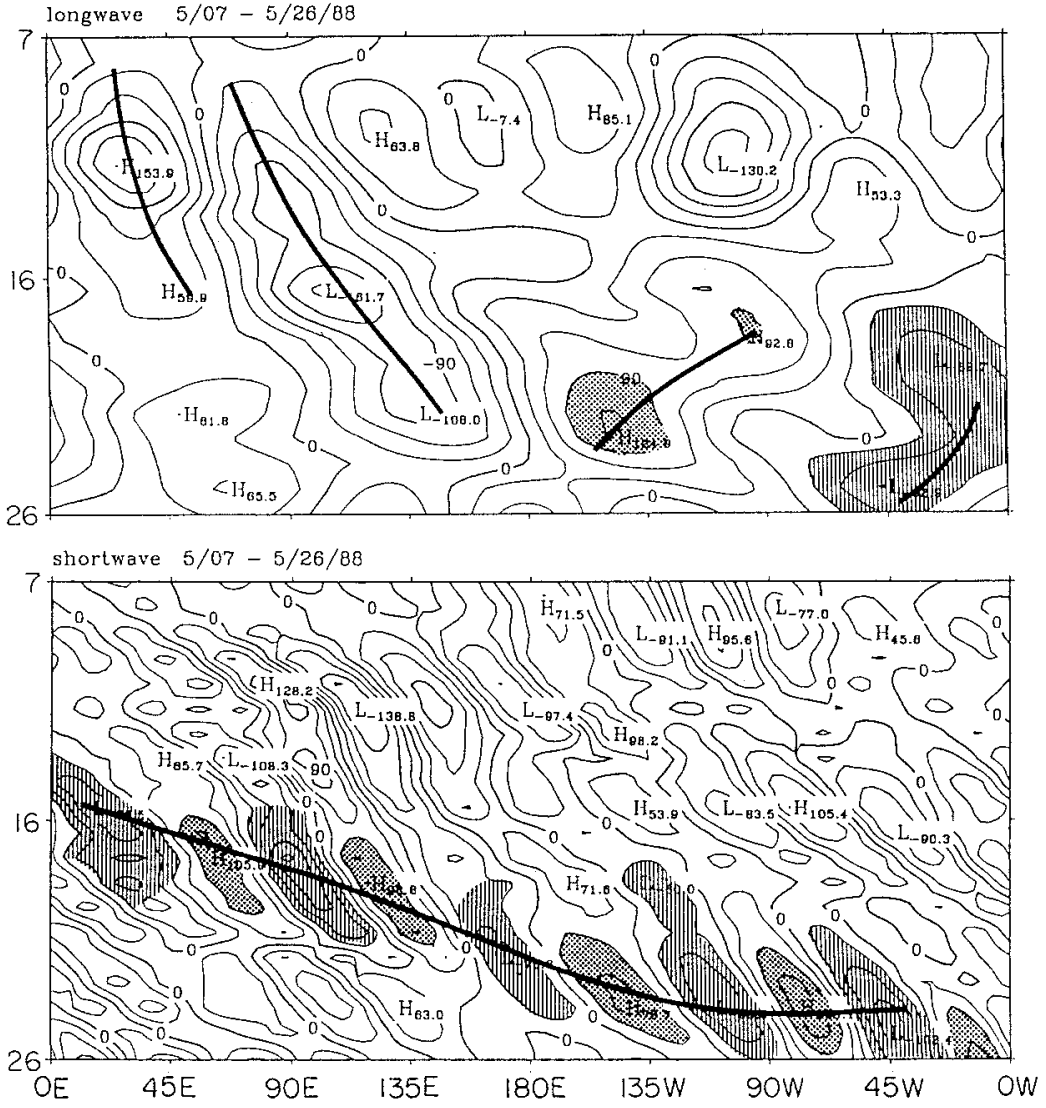

FIG. 8. (Continued) Units: m. (bottom) Same as the top panel except for the short waves (zonal wavenumbers 4-10). Units: $\mathrm{m}$. The dates of frost are shown at the bottom right of the top panel: (a) 8 Jun 1985, (b) 26 May 1988, (c) 13 Jul 1988, (d) 26 Jul 1988, (e) 27 May 1989, (f) 7 Jul 1989, (g) 22 May 1990, (h) 10 Jul 1994, (i) 9 Aug 1994, and (j) composite of all evens.

$(x-t)$ diagram implies downstream amplification. Absence of such a string is what is observed most of the time. In some of the cases we do find a well-defined single string of alternating lows and highs resulting in the freeze. In a few instances we have also noted two adjacent strings of alternating lows and highs that seem to contribute to a sustained freeze. Furthermore, we find that slow-moving or retrogressing long waves were in- deed noted in almost all cases during or preceding the periods of the individual freeze events. Furthermore, the short waves exhibit a rapid eastward motion prior to the freeze and a slowing down around and subsequent to this period.

A composite structure of the downstream amplification is shown in Fig. 8j. This was obtained by using the axis of the downstream amplifying waves for all nine 
(c)

(c) mean $z$. $455-25 S$ 6/24 $-7 / 13 / 80$
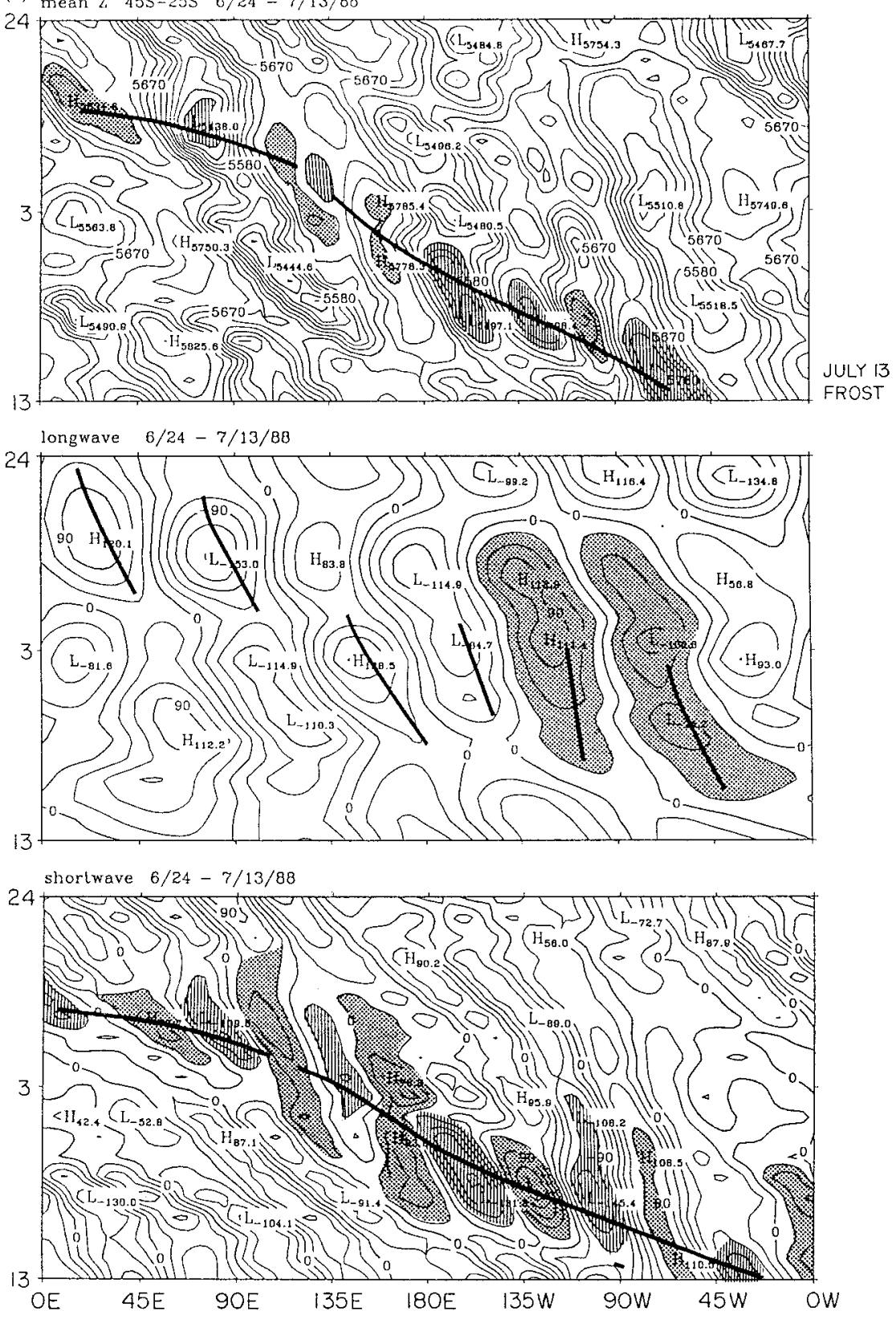

FIG. 8. (Continued)

cases at $180^{\circ}$ and the respective day of passage as an origin. A 10-day composite was prepared with respect to the reference. The composite shows a group velocity of roughly $30^{\circ}$ long day ${ }^{-1}$ and a phase speed of roughly $6^{\circ}$ long day $^{-1}$. The average zonal wavelength of the downstream amplifying waves (trough to trough) is of the order $80^{\circ}$ long. The decomposition of the wave is shown in the middle and bottom panels of Fig. 8j. Quasistationary long waves and eastward-propagating shorter waves with an eastward phase speed of roughly $7^{\circ}$ long day $^{-1}$ were noted. The group velocity of the short-wave packet (wavenumbers 4-10) was nearly identical to that for the total picture shown in the top panel of Fig. 8j. This phenomenon appears quite robust in that the composite structure preserves the features seen for identical episodes.

An unexpected feature of this analysis was the appearance, in a few cases, of a secondary wave train, some 5-8 days subsequent to the primary wave train. This can be noted in the illustration. We shall next se- 
(c)

(c) mear $z$ 45S-25S 0/24 - 7/13/88
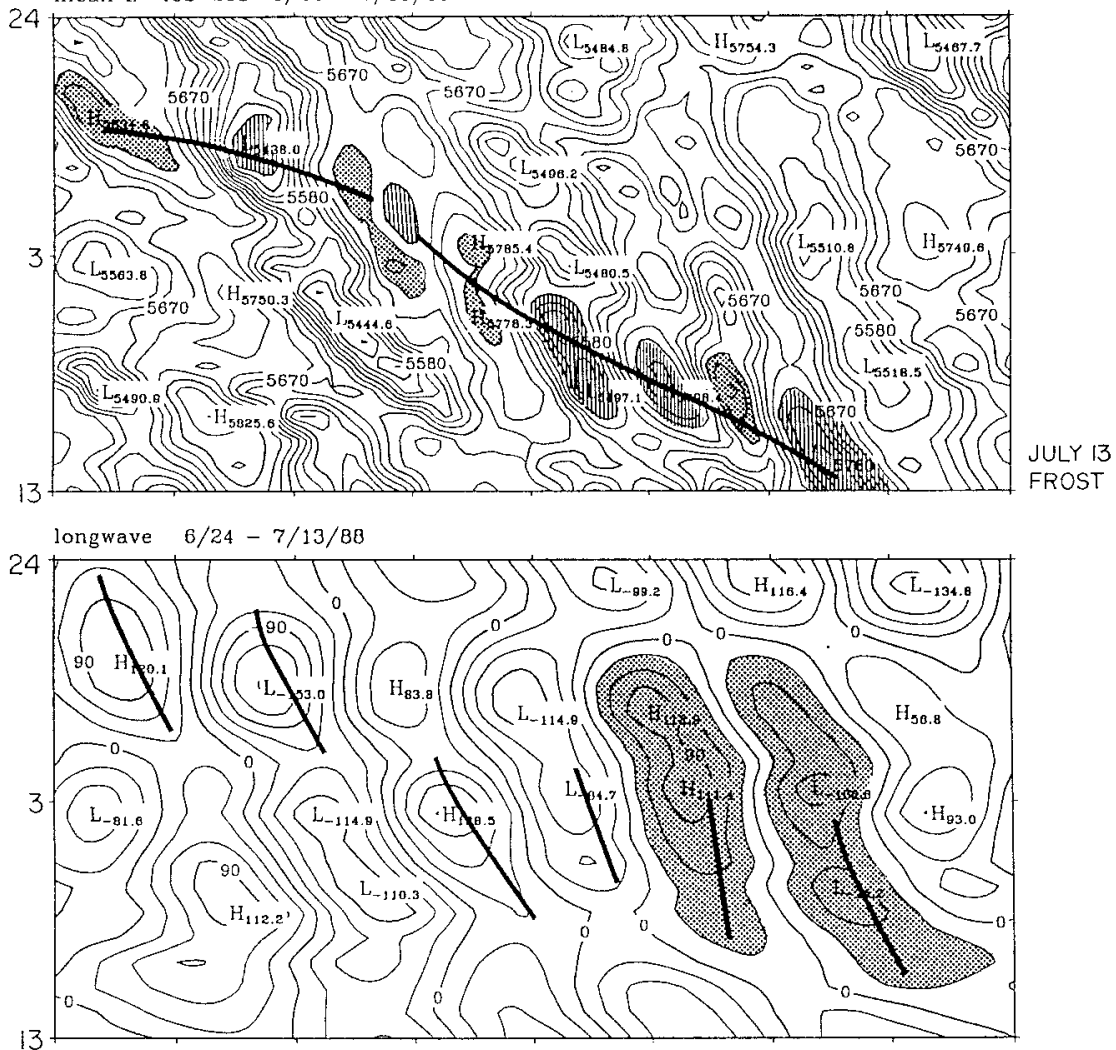

shortwave $6 / 24-7 / 13 / 88$

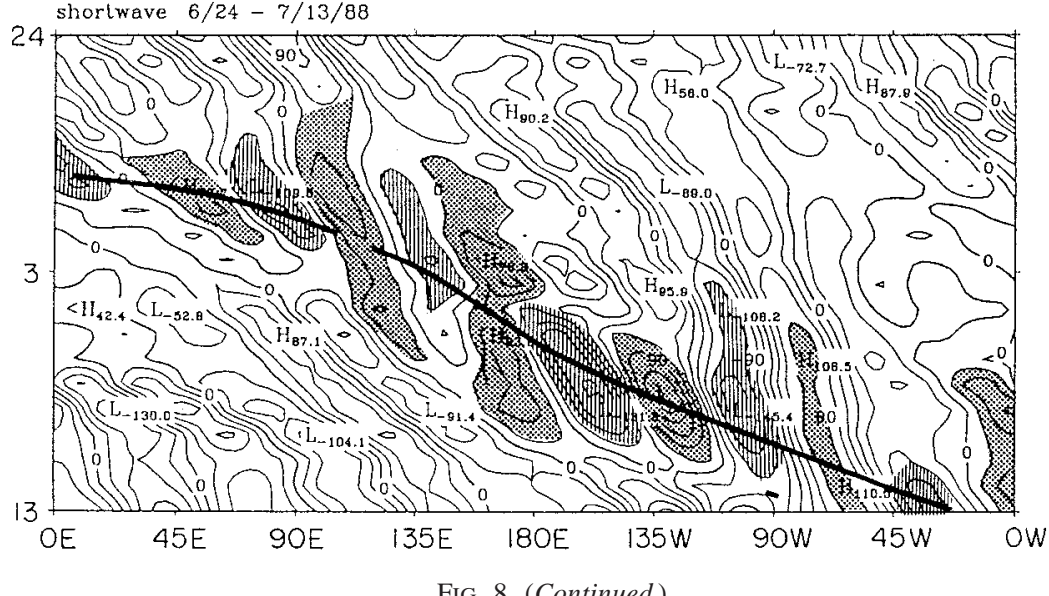

quentially address the zonal breakdown of scales for the various strong freeze events.

\section{a. 20 May-8 June 1985}

A somewhat complex case. Two wave trains were present west of the date line that merged to form a single wave train, exhibiting downstream amplification east of the date line. Figure $8 \mathrm{a}$ illustrates this sequence. The major frost occurred on 8 June 1985 . This was preceded by the amplification of an upper trough east of $45^{\circ} \mathrm{W}$. This case, like all others, displayed the superposition of the long- and the short-wave troughs during the amplification of the major trough east of $45^{\circ} \mathrm{W}$.

\section{b. 7-26 May 1988}

Illustrated in Fig. 8b. The three panels of this diagram are in the same order as the previous set. Here we note a single fast eastward-propagating downstream amplification in the total $Z 500-\mathrm{mb}$ picture, which in turn is broken into slow eastward-propagating longwave components (zonal wavenumbers $1-3$ ), which be- 

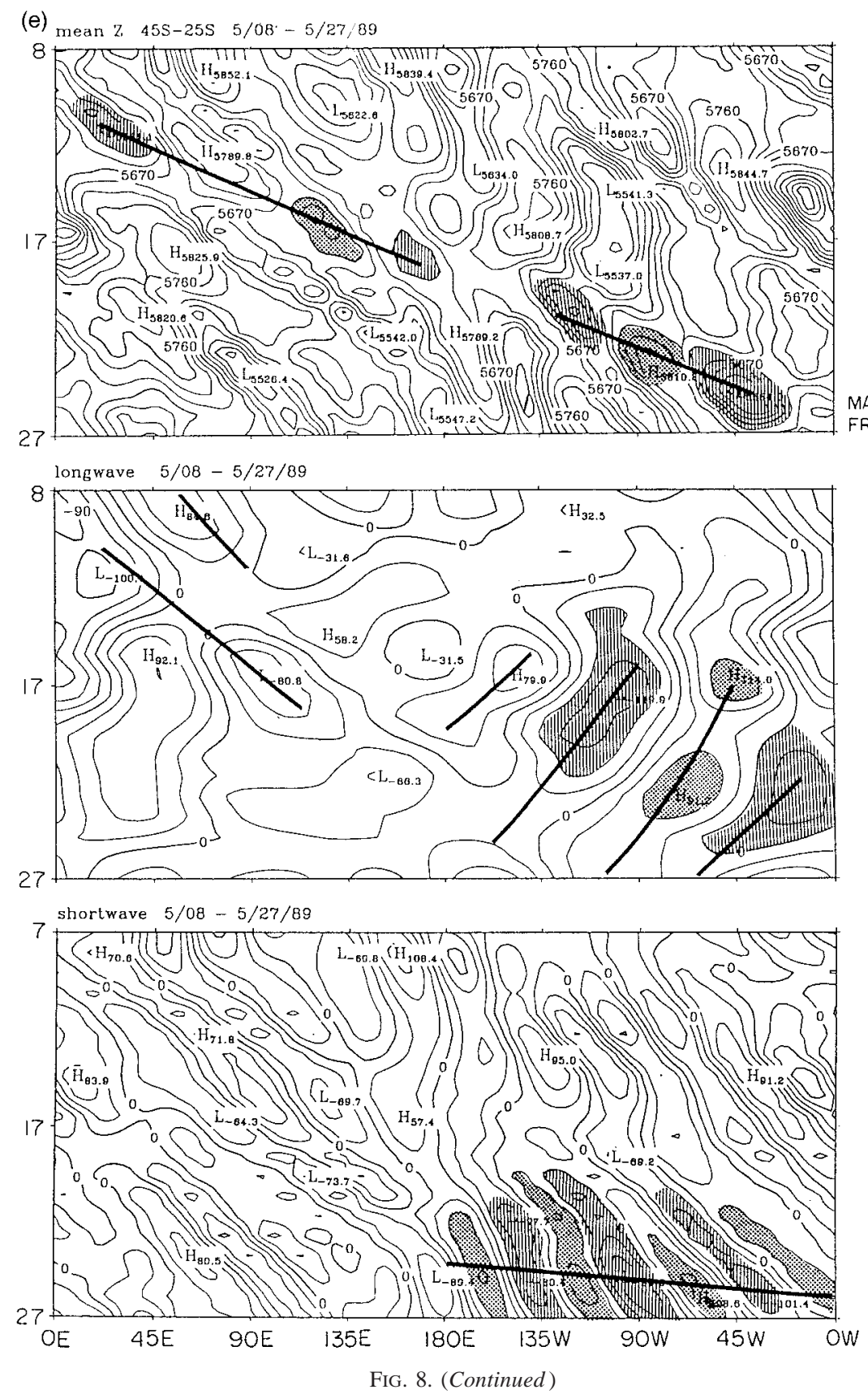

come stationary and retrogress in the latter part of this period. The short-wave component (zonal wavenumbers 4-10) collectively exhibits a downstream amplification. The salient feature is the simultaneous occurrence of a long- and a short-wave trough at $45^{\circ} \mathrm{W}$ around the time of the hard freeze on 26 May 1988. That cold air arrived equatorward at the surface level behind the upper trough near $45^{\circ} \mathrm{W}$. Thus the dynamics and the mechanism of the scale interactions appear worth investigating for the overall understanding of these events.

\section{c. 24 June-13 July 1988}

A classic case of downstream amplification where, again, a superposition of quasi-stationary long waves (zonal wavenumbers 1-3) and a downstream amplifying package of short waves (zonal wavenumbers 4-10) provided the total geometry of the downstream amplification as seen from the $x-t$ diagrams of 500 -mb height field (Fig. 8c). The region to the immediate west of $45^{\circ} \mathrm{W}$ shows a large pressure gradient for the short waves. This trough located near $40^{\circ} \mathrm{W}$ exhibited a su- 


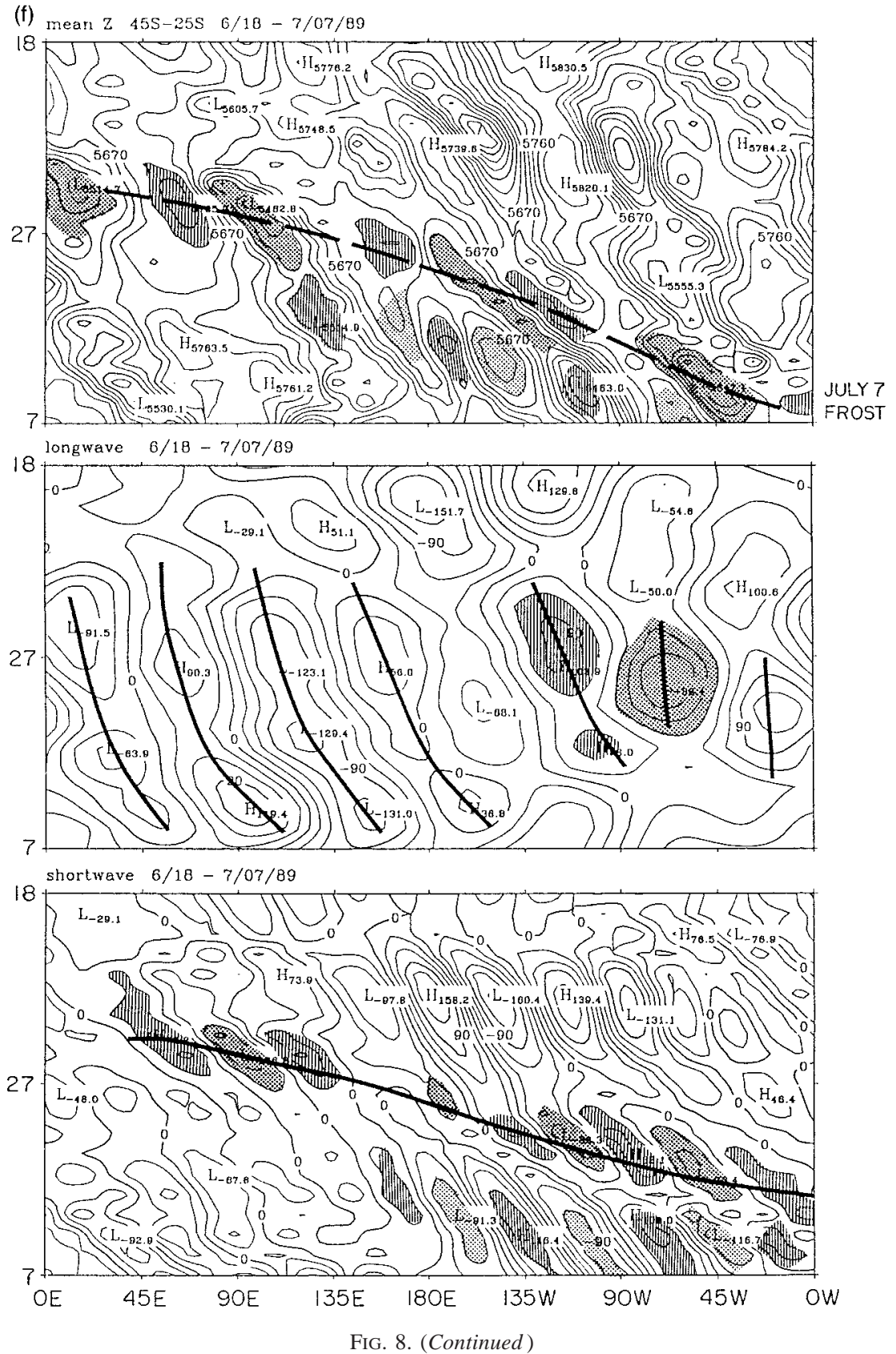

perposition of the long- and the short-wave troughs as the trough of the total picture amplified during the period preceding the frost of 13 July 1988.

\section{d. 7-26 July 1988}

This period saw the arrival of two distinct wave trains from the Pacific (Fig. 8d, in the total picture). The two systems appear to merge into one major system around 23 July. Thereafter the downstream amplification acquired a very large amplitude. The decomposition into waves showed a slowly retrogressing very large am- plitude long-wave family (zonal wavenumbers 1-3). The trough of this family again showed a superposition with the short-wave trough (zonal wavenumbers 4-10) exhibiting a large-amplitude upper trough just to the east of $45^{\circ} \mathrm{W}$ with a sustained southerly component of geostrophic flow around the period of the frost on 26 July 1988.

\section{e. 8-27 May 1989}

A relatively straightforward case. The major wave train appeared to show some weakening around 19 May; 


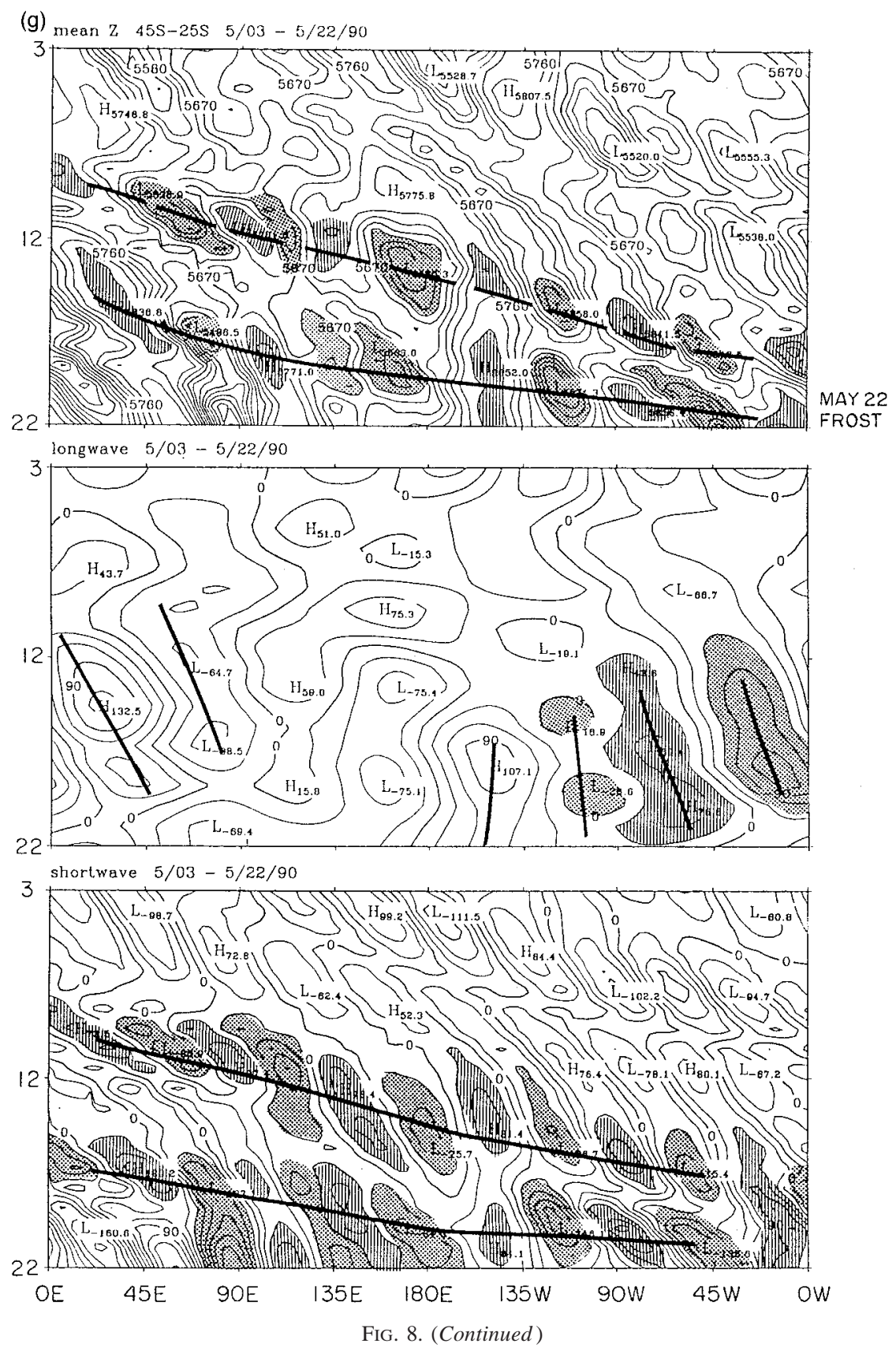

thereafter it strengthened again. Figure 8e illustrates this sequence. The behavior of the long-wave family shows a significant retrogression east of the date line. The short-wave family was very well defined east of the date line after the 19 May. The strong development of the upper trough east of $45^{\circ} \mathrm{W}$ carried a strong southerly flow of cold air that is revealed by the strong packing of contours to the west of this trough. Here again a superposition of the long- and short-wave families of the respective trough systems contributed to the major frost of 27 May.

\section{f. 18 June-7 July 1989}

This case was characterized by a well-defined wave train that exhibited its strongest amplification of an upper trough east of $45^{\circ} \mathrm{W}$ around 4 July. The major frost occurred on 7 July. Figure 8f illustrates this sequence. The long-wave family demonstrated a quasi-stationary phase east of the date line. The short-wave family exhibited a downstream amplification leading to a major superposition of the troughs of the long- and the shortwave families east of $45^{\circ} \mathrm{W}$. 


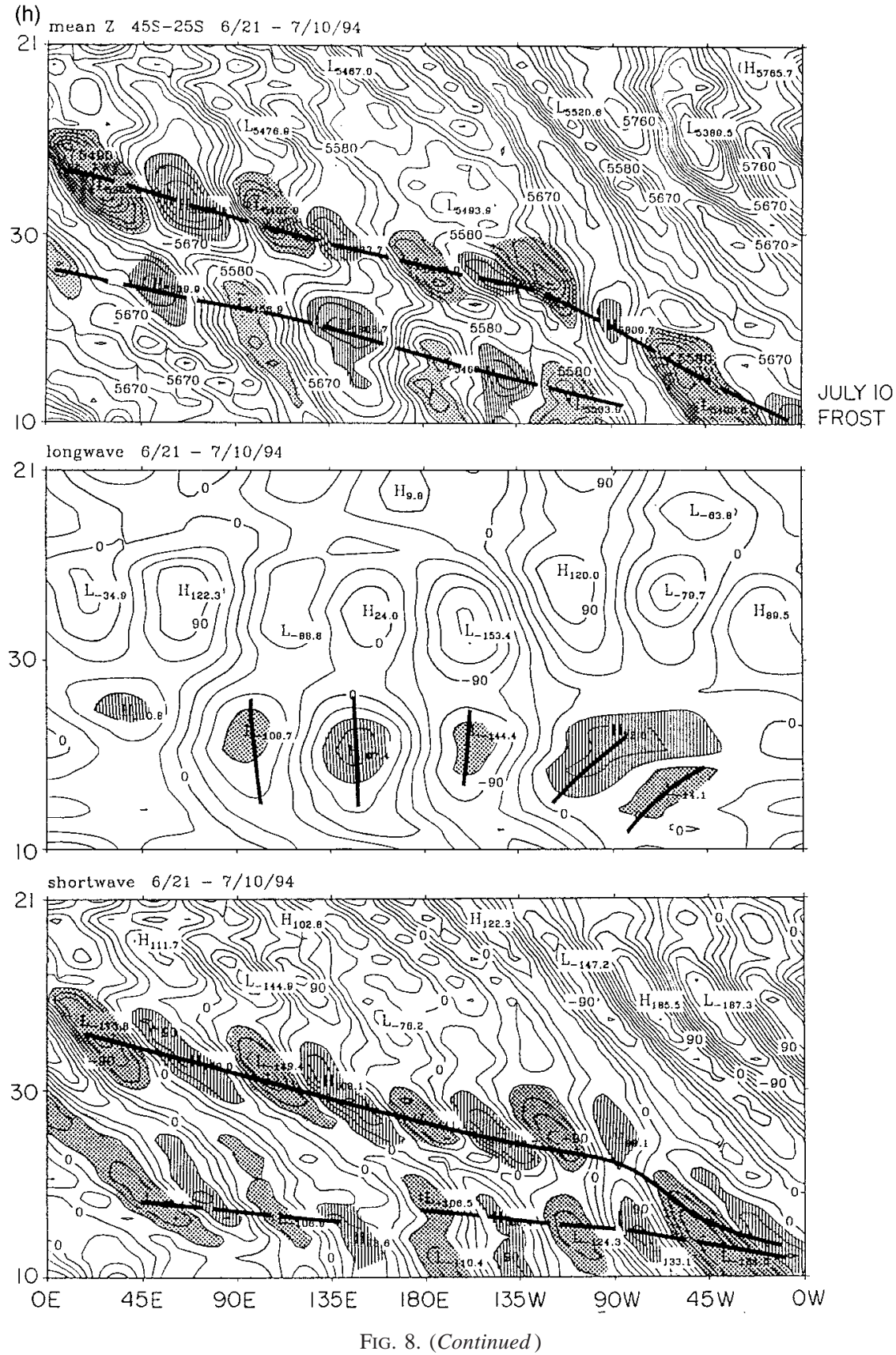

\section{g. 3-22 May 1990}

Figure 8g (top) illustrates the Hovmöller diagram for the $500-\mathrm{mb}$ heights (averaged between $25^{\circ}$ and $45^{\circ} \mathrm{S}$ ) for the period 3-22 May 1990 . The date of intense freeze was 22 May. The striking feature here is the presence of two wave trains that followed each other in succession. This is now an uncommon occurrence. Such multiple features have been illustrated by Schultz et al. (1998) for Northern Hemisphere cold surge events. Around $45^{\circ} \mathrm{W}$ long, the two wave trains were only separated by a few days. This helped in the occurrence of an extended upper trough for an entire week and in the establishment of a cold spell behind the upper troughs of the two wave trains. The longwaves (zonal wavenumbers 1-3) are grouped together in the middle panel. The long waves were very slowly progressing eastward during the early stage of the wave train. Thereafter these waves exhibited a quasi-stationary phase. The short waves (zonal wavenumbers 4-10) are shown in the bottom panel, and they exhibited a downstream amplification that was quite similar to the total picture shown in the top panel. The short- 

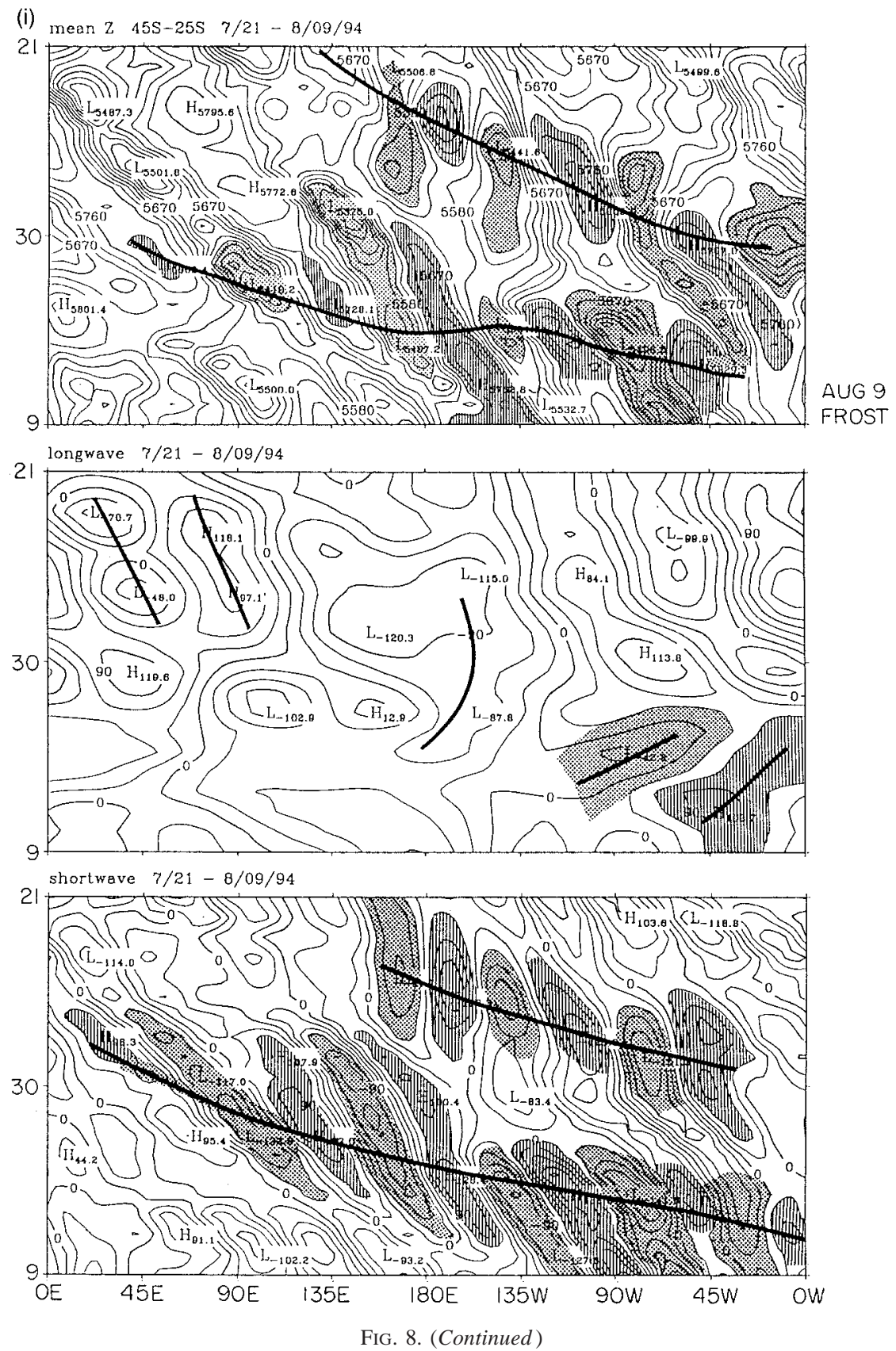

and the long-wave troughs were in phase and had acquired a large amplitude near $45^{\circ} \mathrm{W}$ just prior to the period of this major frost.

\section{h. 21 June-10 July 1994}

A dual wave train that was apparent in the Hovmöller diagrams of the total 500-mb heights (averaged between $25^{\circ}$ and $45^{\circ} \mathrm{S}$ ) and the short-wave components (for zonal wavenumbers 4-10; Fig. 8h) characterized the period. The two wave trains demonstrated a merger around 4 July; thereafter an explosive growth of the upper trough west of $45^{\circ} \mathrm{W}$ was noted. During this period the long waves, which were quasi-stationary, initially exhibited a retrogression. The trough of the long-wave system showed a superposition of phase with respect to the trough of the short-wave system during the major amplification of the upper trough resulting in the frost of 10 July.

\section{i. 21 July-9 August 1994}

Another case of dual downstream amplifying wave trains that demonstrated many of the same character- 

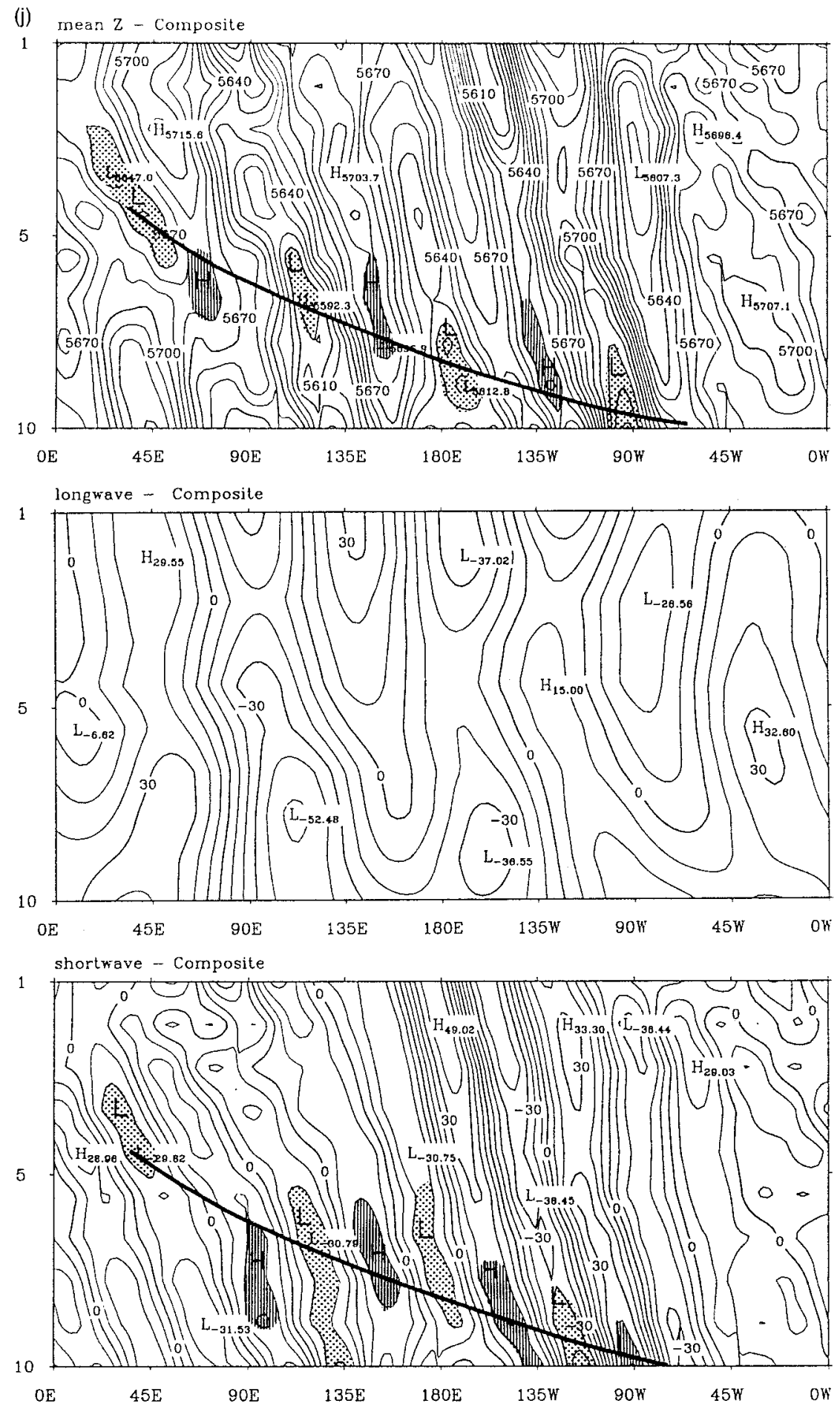

FIG. 8. (Continued)

istics as some of the previous cases. However, the two wave trains remained essentially separate during this period. Both wave trains were very active east of the date line. The long waves that were initially progressive became stationary around the date line and retrogressed east of the date line. Figure $8 \mathrm{i}$ illustrates the respective Hovmöller diagrams of the $500-\mathrm{mb}$ heights. The short waves clearly showed a trough east of $45^{\circ} \mathrm{W}$ where it was superposed by a long-wave trough, resulting in the final large-amplitude trough and the frost on 9 August. 
The two wave trains, although seemingly separate, did share long-lasting troughs and ridges of the final stage. Thus, the frost was indeed related to the presence of a long-lasting system that arose from the two somewhat separate wave trains.

\section{Dominant scales during the freeze event}

In the rest of the paper, we shall be addressing the details of a severe freeze event of 26 June 1994. We have divided this event into three phases. Phase I, prior to the freeze event, covers the period of 21-June 25 1994; phase II, during the freeze event, covers the period of 26-27 June 1994; and phase III, after the freeze event, covers the period of 28-30 June 1994. Figures 9a-c illustrate the variance spectra of $500-\mathrm{mb}$ geopotential (averaged between $25^{\circ}$ and $45^{\circ} \mathrm{S}$ ) plotted as a function of zonal wavenumber for the three phases, that is, (a) phase I, (b) phase II, and (c) phase III. This is based on compositing the results from each of the severe frost cases. It is apparent that the dominant scales of the 500$\mathrm{mb}$ heights are within the first 10 zonal wavenumbers. Features that stand out are large variances reside in the planetary scales (wavenumbers 1-3) and in the synoptic scales (wavenumbers 4-9) prior to the freeze in phase I. During the freeze event, identified by Fig. $9 \mathrm{~b}$ for phase II, the spectra looks similar to phase I except that zonal wavenumber 9 stands out, contributing a very large percent variance. Subsequent to the freeze, Fig. 9c, a dominant planetary scale and a pronounced synoptic scale for zonal wavenumbers $4-8$ with the largest variance for zonal wavenumber 6 is noted. Overall the synoptic scale appears to be most prominent during the period of the freeze event.

\section{Overall energetics}

After recognizing that the downstream amplification, illustrated in Fig. 3, can be broken down into slowmoving long waves and faster-moving short waves, we ask, do these waves interact during the trough amplification? A purpose of the energetics discussed below is to elucidate that scale interaction (i.e., energy exchanges for long waves to the shorter waves do occur during this amplification). We shall next be looking at the scale interactions of the freeze event. In Figs. 10a$\mathrm{c}$ we present scale interaction, among these aforementioned waves, following Saltzman (1970). Here the Figs. $10 \mathrm{a}, \mathrm{b}, \mathrm{c}$, respectively, denote the results for the period prior to the freeze, during the freeze, and for the postfreeze periods. All energy exchanges are vertical integrals from 100 to $1000 \mathrm{mb}$ and cover the latitude belt $45^{\circ}-25^{\circ} \mathrm{S}$. The units of energy quantities are $\mathrm{J} \mathrm{kg}^{-1}$, and the units for energy exchange are $10^{-5} \mathrm{~W} \mathrm{~kg}^{-1}$. In Fig. 10 , the entries on the left denote energy exchanges among the different waves and those on the right denote energy exchange between the waves and the zonal flows. Within each box, looking down, the results for increas- (a)

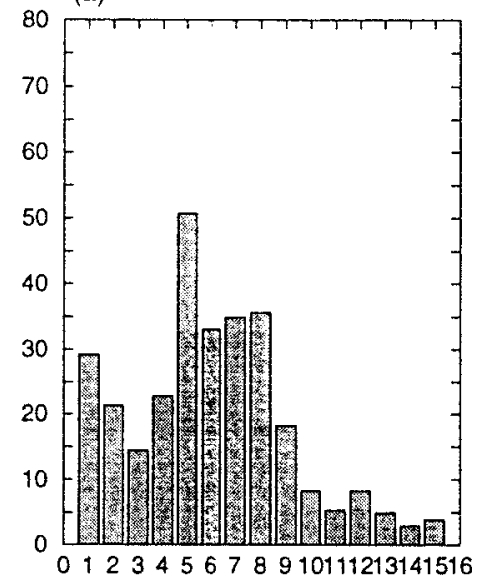

(b)

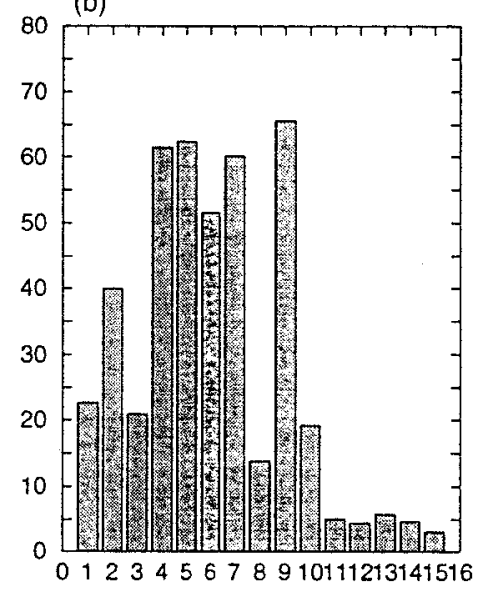

(c)

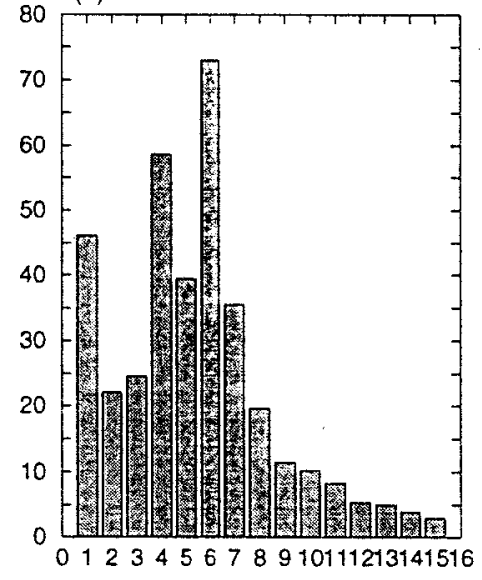

FIG. 9. (a)-(c) The variance spectra of 500-mb geopotential height plotted as a function of zonal wavenumbers for the prefreeze, during the freeze, and the postfreeze periods, respectively. 


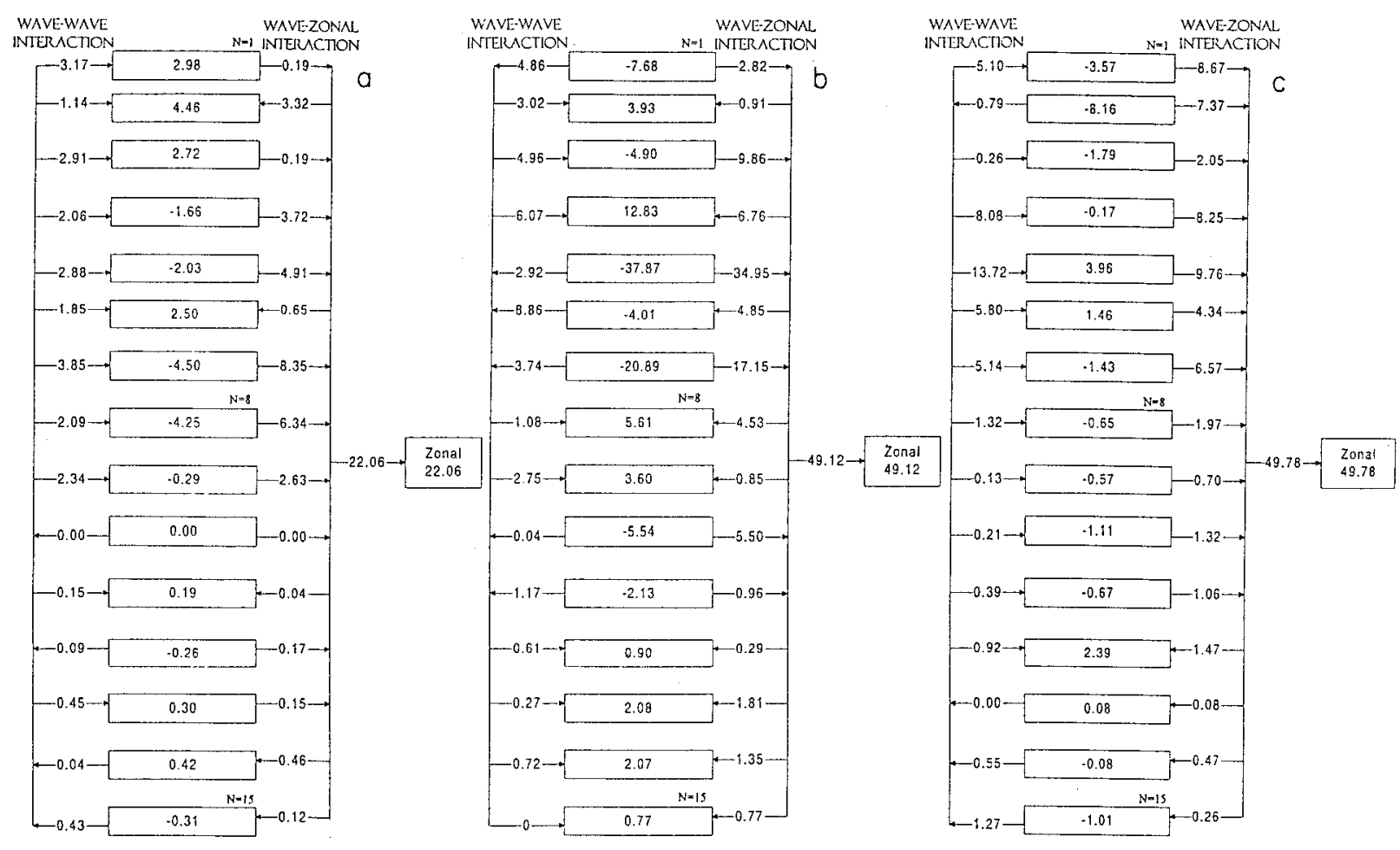

FIG. 10. Wave-wave and wave-zonal interaction results for wavenumbers 1-15 are listed in sequence from top to bottom. Units of energy exchanges are $10^{-5} \mathrm{~W} \mathrm{~kg}^{-1}$ : (a) prefreeze period, 21-25 Jun 1994, (b) during the freeze period, 26-27 Jun 1994, and (c) postfreeze period, 28-30 Jun 1994. Entries in the central box show the net gain of energy for a particular wavenumber from the difference in contributions for wave-wave and the wave zonal interactions. The net gain of kinetic energy by the zonal flows from waves is shown within the single box to the right in each panel.

ing sequence of the first 15 zonal wavenumbers are shown. The entries within the central box denote the convergence of flux of energy that arises from the difference between gains and losses of energy from the energy exchanges among the respective wavenumbers and to other waves and the zonal flows. During phase I (Fig. 10a), prior to the freeze event most waves transferred energy to the zonal flows. Substantial gains of energy were also experienced by wavenumbers 1-9 when they interacted with other waves. Taking both the wave-wave and the wave-zonal contributions, we note that long waves (zonal wavenumbers 1-3) showed a net gain of energy from these interactions. It should be noted that this does not include the baroclinic (in scale) contributions, those discussed in section 6b. Zonal wavenumbers 7 and 8 exhibit the largest loss of energy from the combined effects of wave-wave and the wavezonal processes. During the freeze event a substantial transfer of energy from the waves to the zonal flows occurs. The largest contributions to this transfer occur for zonal wavenumbers $1,3,5,7$, and 10. The longwave components (zonal wavenumbers 2 and 3 ) gain energy from wave-wave interaction, whereas synopticscale wave (wavenumbers 5, 6, and 7) lose energy from wave-wave interactions, and wavenumbers 4,8 , and 9 show gains from wave-wave interactions. Among the synoptic-scale waves, zonal wavenumbers 4,8 , and 9 exhibit a net gain of energy from the combined effects of wave-wave and wave-zonal interactions. The results for the postfreeze period, Fig 10c, show a net loss of energy for the long waves from the combined effects of the wave-wave and wave-zonal interactions, and the transfers to the zonal flows are large. The most prominent gain from wave-wave interaction is experienced by zonal wavenumber 5 , which exhibits a net gain of energy from combined effects of wave-wave and wavezonal interactions. Most waves lose energy to the zonal flows. Overall the results shown in Figs. 10a-c exhibit considerable uncertainties; these are usually attributed to large standard errors in the estimates for individual wave components (Saltzman 1970). Although the standard errors of the energy exchange are somewhat large due to data uncertainties, they are not very large if data records are long. Such results can be improved by an averaging over the long, synoptic, and short-wave components. These are presented in section $6 \mathrm{~b}$.

\section{Mechanisms of the large-amplitude trough related to the freeze event}

Scale interactions were computed following the methods proposed by Saltzman (1970), Kanamitsu et al. (1972), and Krishnamurti (1980). This procedure is outlined in appendix B of this paper. The scale interactions 
may be somewhat different during the three phases of the 26 June 1994 event. A variance spectra of zonal harmonics was first evaluated in order to determine the dominant zonal scales of the large-amplitude trough over South America during the freeze events. This analysis revealed that the dominant scales were in the wavenumber range of 4-10 over the middle-latitude belt between $25^{\circ}$ and $45^{\circ} \mathrm{S}$ over the Southern Hemisphere; we shall be focusing on these scales in the following computation of scale interactions. Figures $9 \mathrm{a}-\mathrm{c}$ illustrate such a plot of the amplitude of the various zonal harmonics. The date of intense freeze for the June 1994 event was around the 26th of the month.

\section{a. Barotropic triad interactions}

Here we have considered the scale interactions of wavenumbers 1-10 with all other relevant pairs of waves. Figures $11 \mathrm{a}-\mathrm{j}$ illustrate the triad interactions for phase I. This period is characterized by wave trains that clearly exhibited a downstream amplification. During this initial phase of the excitation of the wave train triad interactions showed the largest growth of kinetic energy for wavenumber 9 from its interaction with all relevant pairs illustrated in Fig. 11i. These pairs satisfy the selection rule: $m=n \pm p$, where $m=9$ and $n, p$ are the other two members of the triad interactions. All of the energy exchanges were integrated through the depth of the troposphere over the latitude belt $25^{\circ}-45^{\circ} \mathrm{S}$. Wavenumber 9 gains energy from its interactions with other pairs within the wavenumber range $1-10$. We also note a gain of energy for wavenumbers $4,5,6$, and 7 for most of their triad interactions with other pairs of waves. Overall we note that among the long waves, zonal wavenumber 1 loses energy in its triad interactions, the largest losses are noted in its interaction with the pairs 7 , 8 and 8,9 . The behavior of zonal wavenumbers 2 and 3 were not very substantial.

During phase II (Figs. 12a-j, i.e., the freeze period between 26 and 27 June), the long waves 2 and 3 show an overall gain of energy from their triad interactions with other pairs of waves. Wavenumber 1 shows an overall loss in this regard. Among the synoptic-scale waves, wavenumber 4 exhibits a net gain of energy from its interaction with other pairs of waves, whereas we note a net loss for zonal wavenumber 7 and a net gain for wavenumbers $8-10$ by these nonlinear interactions with other waves. This implies that, overall, the barotropic process continues to strengthen the synoptic scales from triad interactions.

During phase III (Figs. 13a-j, the postfreeze period) the long waves (zonal wavenumbers 1-3) exhibit a small net gain, which is also reflected for the synoptic-scale waves with zonal wavenumbers 4-6. Wavenumbers 7 and 8 do not exhibit any substantial energy loss or gain from triad interactions.

\section{b. Baroclinic-scale interactions}

Basically this describes the energy exchanges that arise from its scale contributions (i.e., $m=n$ ) from the covariance of vertical velocity and temperature. This quadratic nonlinearity precludes contributions among different scales $(m \neq n)$ from vertical overturnings. This turned out to be the dominant energy conversion for the synoptic scales; that is, eddy available potential energy is converted to eddy kinetic energy for the zonal wavenumbers 4-10 (Figs. 14a-c). In this illustration, we have presented the overall energetics relevant to zonal wavenumbers 4-10. During all of the phases before, during, and after the frost, the baroclinic energy exchanges are dominant. This implies that we are dealing with a "baroclinic wave train" and a "baroclinic downstream amplification." These wave trains that traverse across the Pacific Ocean and arrive over South America contain within them large vertical overturnings of warmer air rising and colder air sinking on a zonal-vertical plane; that is, they denote synoptic-scale, thermally direct, east-west circulations. We do note some distinctions among these three phases. The baroclinic contributions to the gain of eddy kinetic energy of the synoptic scales for the different phases are before frost $339 \times 10^{-5} \mathrm{~W}$ $\mathrm{kg}^{-1}$, during the frost $397 \times 10^{-5} \mathrm{~W} \mathrm{~kg}^{-1}$, and subsequent to the frost $307 \times 10^{-5} \mathrm{~W} \mathrm{~kg}^{-1}$. During the period of the frost, where the amplitude of the middlelatitude trough is at a maximum, the baroclinic contributions are the largest. These differences among the phases are not very large. One wonders whether the wave train itself is inherently a barotropic wave that successively sees baroclinic developments within each downstream-amplifying synoptic system or whether it is indeed a baroclinic wave train. Examination of the vertical velocity and the temperature fields portrayed on Hovmöller $(x-t)$ diagrams clearly suggests that this is indeed a propagating, baroclinic phenomena where the temperature and vertical velocity fields also exhibit a downstream amplification individually. Thus it appears that we are dealing with a robust baroclinic wave train.

In these overall summary diagrams, the wave-zonal contributions on the synoptic scales show a systematic transfer of eddy kinetic energy to the zonal kinetic energy (for zonal wavenumbers 4-10). This barotropic process has a stabilizing influence on the synoptic-scale waves throughout the period (i.e., before, during, and after the freeze). These exchanges are about an order of magnitude smaller than the in-scale $(m=n)$ baroclinic energy exchanges.

This summary diagram also provides the results of the barotropic nonlinear triad interactions for the synoptic scales 4-10. During the respective phases (before, during, and after the frost), the values of these exchanges were $33 \times 10^{-5} \mathrm{~W} \mathrm{~kg}^{-1}, 6 \times 10^{-5} \mathrm{~W} \mathrm{~kg}^{-1}$, and $19 \times$ $10^{-5} \mathrm{~W} \mathrm{~kg}^{-1}$. The initial growth of the synoptic scale was, thus, also contributed to by the barotropic nonlinear 

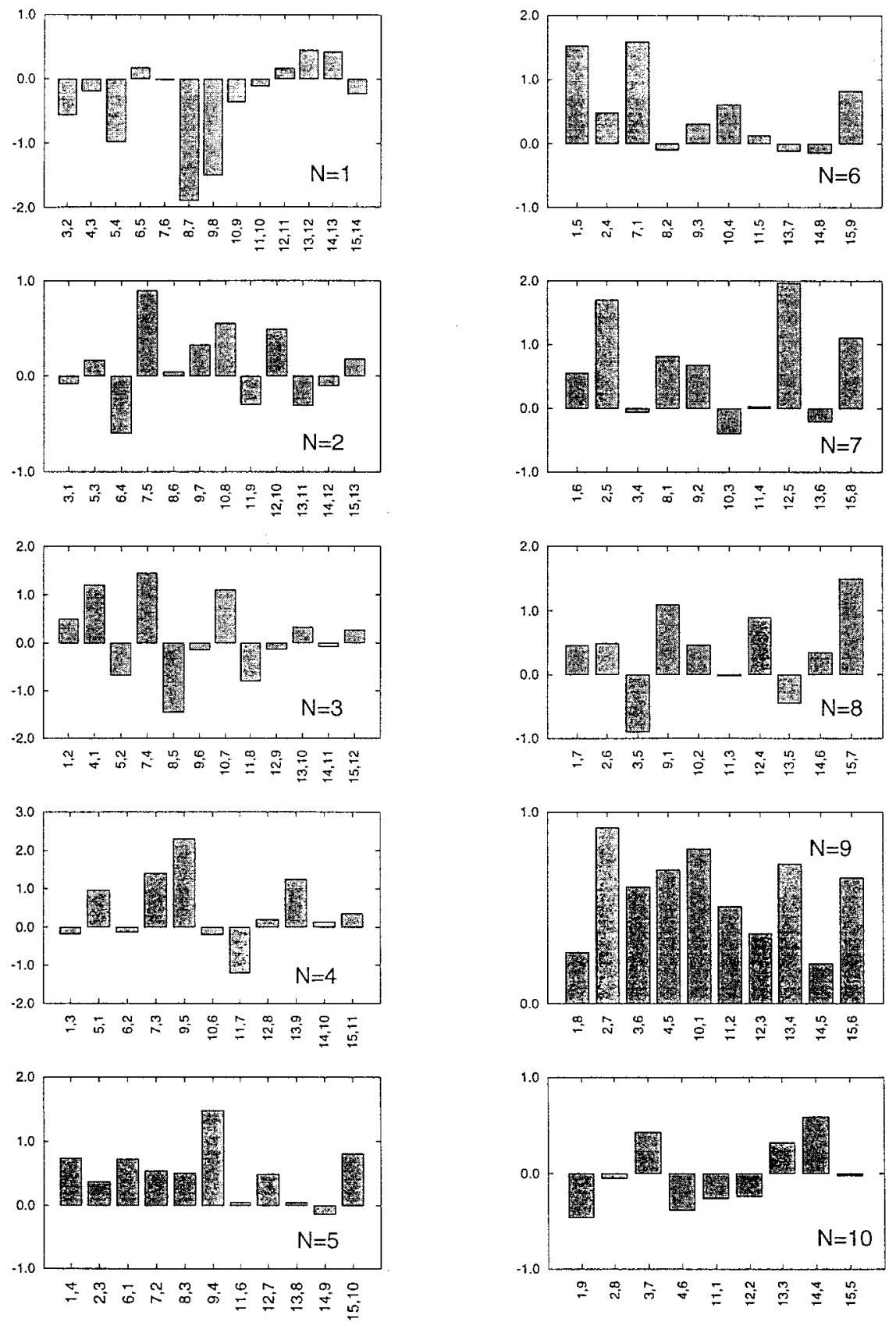

FIG. 11. (a)-(j) The net gain of energy by individual wavenumbers arising from triad interactions with a pair of other waves. Ordinate shows rate of energy gain in units $10^{-5} \mathrm{~W} \mathrm{~kg}^{-1}$; abscissa shows the pairs of wavenumbers of the triad. These 10 panels on each illustration cover the triad interactions of wavenumber $1-10$ (prefreeze period).

triad interactions. Thereafter the value of this exchange were smaller.

\section{Concluding remarks}

Most major freeze events over southeastern Brazil are accompanied by major synoptic- to planetary-scale changes in the pressure system over an extensive part of the Southern Hemisphere. The large-amplitude trough of the middle latitudes, which extends well into the Southern Hemisphere Tropics, has an interesting history of antecedents. A fast eastward-moving downstream amplification can be seen on Hovmöller $(x-t)$ diagrams during these events. These features can be zonally decomposed into a family of eastward-moving shorter synoptic-scale waves and planetary-scale com- 

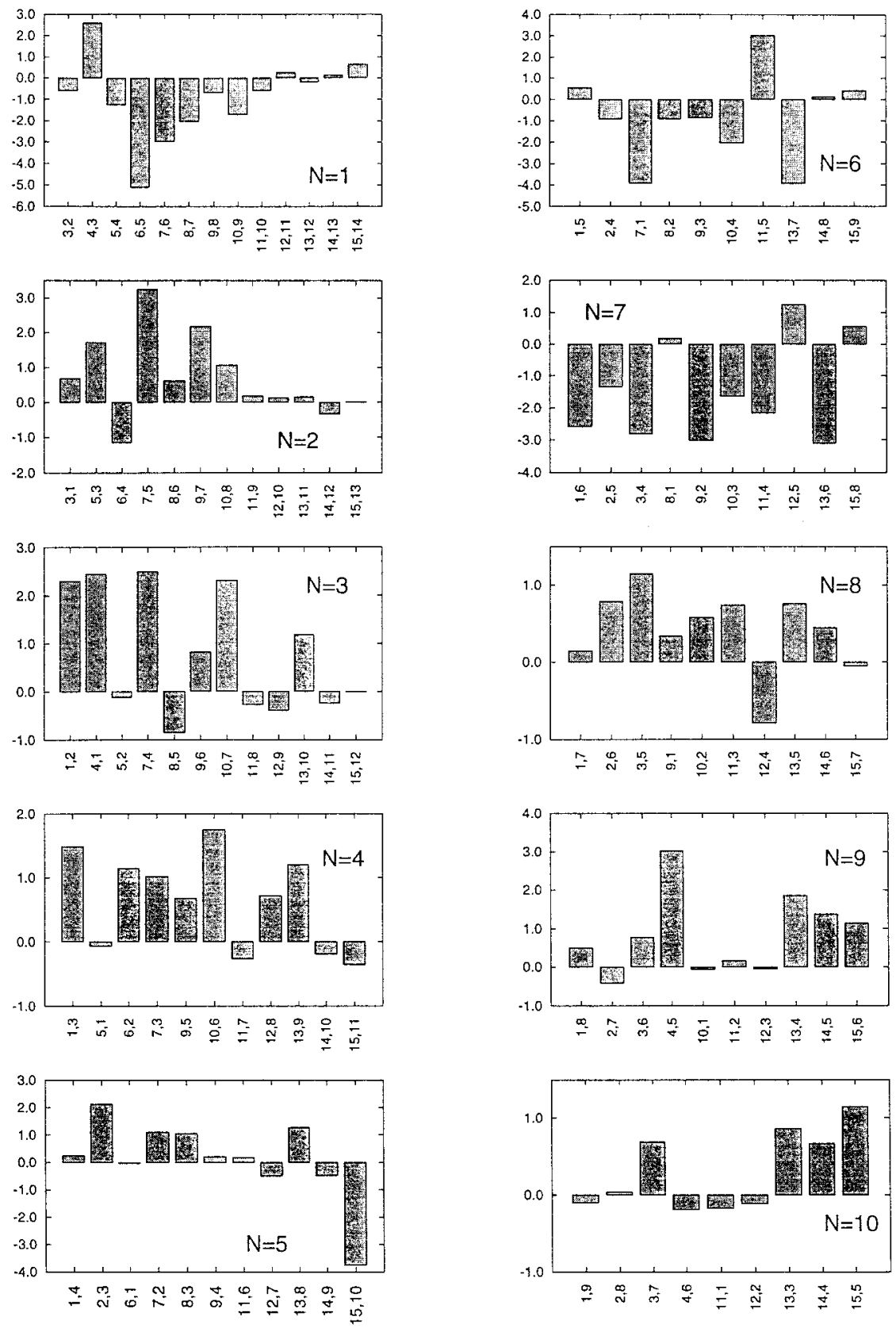

FIG. 12. (a)-(j) Same as Fig. 8 but for the freeze period.

ponents that become quasi-stationary as the synopticscale trough amplifies. We show interesting scale interactions during a 10-day period. This period is divided into three parts, that is, prior to, during, and after the freeze event. Computation of energetics in the wavenumber domain shows that the period prior to the freeze event where the wave train exhibiting downstream amplification was prominent and was dominated by the barotropic nonlinear energy exchanges among wave components. During this period the synoptic-scale features centered around zonal wavenumber 9 received en- ergy from lower wavenumbers (such as zonal wavenumbers 1 and 3) via barotropic triad interactions. The immediate period of the freeze, when the upper trough had acquired its largest amplitude, was characterized by baroclinic growth. This is manifested by a large covariance of the vertical velocity and temperature on the synoptic scale. This being a quadratic nonlinearity permits energy exchanges for eddy available potential energy to eddy kinetic energy only on the scales of vertical overturnings. By far the most important result on scale interaction is that the baroclinic (in scale) contributions 

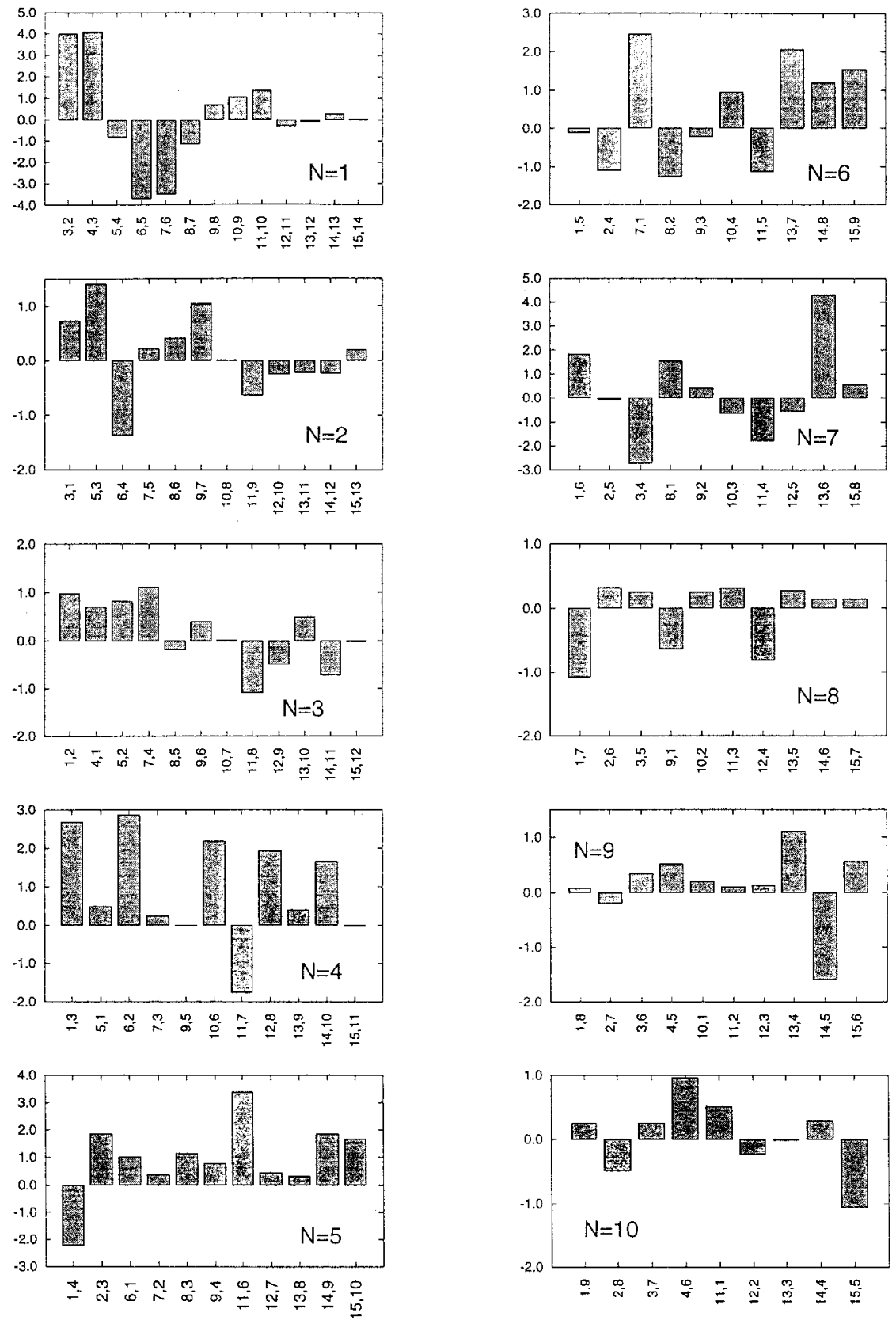

FIG. 13. (a)-(j) Same as Fig. 8 but for the postfreeze period.

to the generation of eddy kinetic energy from eddy available potential energy are the most prominent throughout the history of this large-amplitude freeze generating upper trough. This wave train appears to generate a baroclinic downstream amplification. Although the barotropic nonlinear processes, such as wave-wave triad interaction, for the synoptic-scale waves (zonal wavenumbers 4-10) are significant, they are still an order of magnitude smaller than the baroclinic contribution. By far, zonal wavenumber 9, among the synoptic-scale waves, is the most prominent zonal scale during the downstream amplification. Phenomenologically a wave train containing planetary and these synoptic scales show largely a baroclinic downstream amplification. The 500-mb trough acquires its largest amplitude as it arrives over South America bringing in cold air from the South Polar latitudes with a resulting freeze over the southeastern Brazilian region. The period subsequent to the freeze was also characterized by large contributions to the growth of eddy kinetic energy of synoptic-scale waves by the baroclinic process. During this period, the barotropic triad interactions contributed less 

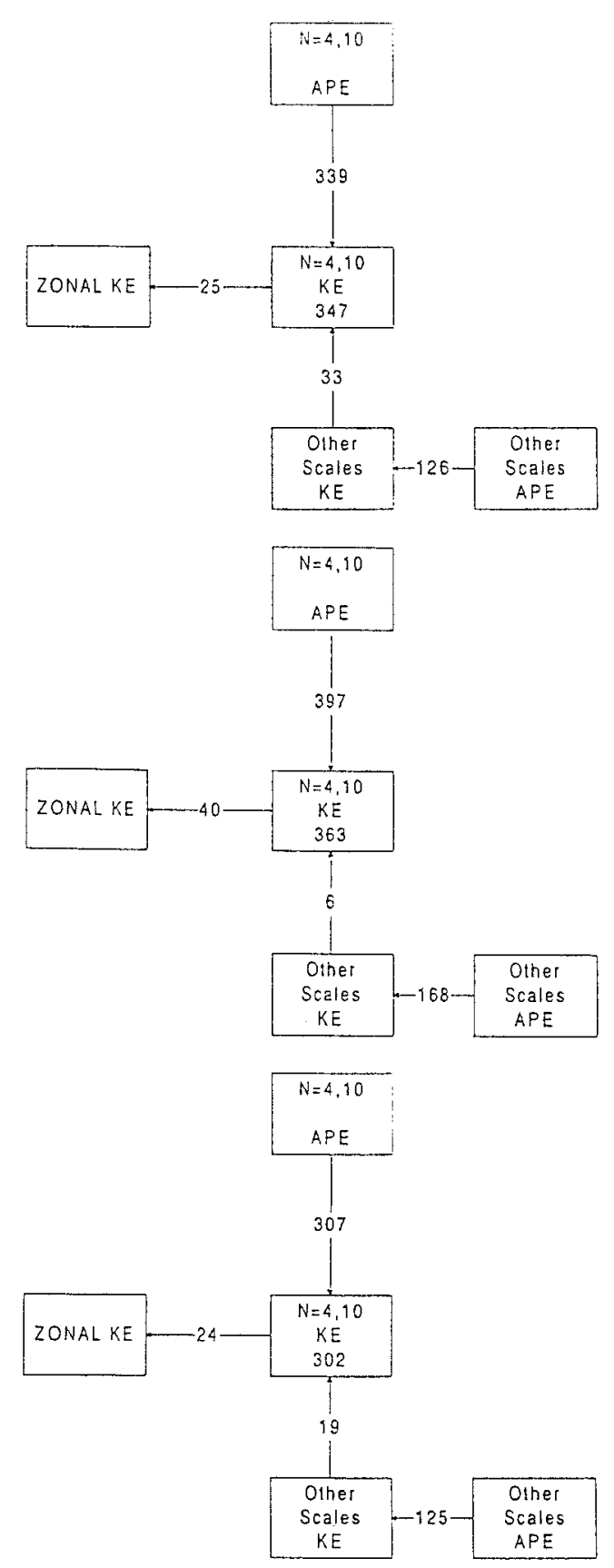

FIG. 14. (a)-(c) Energy exchanges relevant to the synoptic scales (zonal wavenumbers 4-10). The central box denotes the net gain of energy (units, $10^{-5} \mathrm{~W} \mathrm{~kg}^{-1}$ ) by these scales. The zonal kinetic to eddy kinetic energy for these scales are shown at the left of this central box. The in-scale eddy available potential energy to eddy kinetic energy for these scales are shown at the top of the central box. Interactions with other scales (wave-wave interactions) are shown below this box and the eddy available potential to eddy kinetic energy for other scales are shown in the bottom right: (a) prefreeze period 21-25 Jun 1994, (b) the freeze period 26-27 Jun 1994, and (c) the postfreeze period 28-30 Jun 1994. to the growth of eddy kinetic energy of the synopticscale waves as compared to the preceding periods. An accurate prediction of the freeze event on the mediumrange timescale appears to be feasible. Since these are closely tied to synoptic- and planetary-scale weather events, a reasonable high-resolution global model can a indeed predict the wave train exhibiting the downstream amplification. We have demonstrated that local aspects of the freeze can be handled by a very high resolution regional spectral model. It should be possible to make use of the various modeling approaches outlined here to address the issues of severe frosts.

Acknowledgments. The research reported here was supported by the following two IAI grants: Grant S9679899 and Grant ISP-11-112.

\section{APPENDIX A}

\section{Symbols Used}

Symbol Meaning of symbol

$\begin{array}{ll}b & \text { Radius of the earth } \\ f & \text { Coriolis parameter } \\ g & \text { Acceleration of gravity } \\ p & \text { Pressure } \\ T & \text { Temperature } \\ u, v & \text { Zonal and meridional wind components } \\ \omega & \text { Vertical velocity in isobaric coordinates } \\ z & \text { Height of pressure surface } \\ \lambda & \text { Longitude } \\ \phi & \text { Latitude } \\ \sigma & \text { p/ps } \\ t & \text { Time } \\ \rho & \text { Density } \\ K_{n} & \text { Kinetic energy for a zonal harmonic } n \\ \phi_{S}, \phi_{N} & 50^{\circ} \mathrm{S} \text { and } 20^{\circ} \mathrm{S}, \text { respectively } \\ A_{p} & \partial A / \partial p \\ U, V & \text { Fourier transform of } u, v \text {, respectively } \\ A(o) & \text { Zonal mean of A } \\ A(n) & \text { Zonal wavenumber } n \text { component of A }\end{array}$

\section{APPENDIX B}

\section{Energy Exchange in an Open System}

The equations used in this study are as follows:

$$
\begin{aligned}
\frac{\partial \phi}{\partial t} & +\frac{u}{a \cos \phi} \frac{\partial u}{\partial \lambda}+\frac{v}{a} \frac{\partial u}{\partial \phi} \\
& =-\frac{g}{a \cos \phi} \frac{\partial z}{\partial \lambda}+v\left(f+\frac{u \tan \phi}{a}\right) \\
\frac{\partial v}{\partial t} & +\frac{u}{a \cos \phi} \frac{\partial v}{\partial \lambda}+\frac{v}{a} \frac{\partial v}{\partial \phi} \\
& =-\frac{g}{a} \frac{\partial z}{\partial \phi}-u\left(f+\frac{u \tan \phi}{a}\right)
\end{aligned}
$$




$$
\begin{aligned}
\frac{\partial z}{\partial p} & =-\frac{1}{\rho g}, \\
\frac{1}{a \cos \phi} \frac{\partial u}{\partial \lambda}+\frac{1}{a} \frac{\partial v}{\partial \phi}-\frac{\tan \phi}{a} v+\frac{\partial \omega}{\partial p} & =0 .
\end{aligned}
$$

Equations (B1) and (B2) are the horizontal equation of motion, while (B3) is the hydrostatic equation, and (B4) the continuity equation.
These equations may be transformed to the wavenumber domain, following Saltzman (1957), by the use of Fourier transformation functions. The equations can then be manipulated to derive an expression for the rate of change of the kinetic energy of any wave component $\mathrm{n}$ in terms of other meteorological variables. This equation is then integrated over the latitude belt $\phi_{S}$ to $\phi_{N}$ to obtain

$$
\begin{aligned}
& \int_{\phi_{S}}^{\phi_{N}}\left(k_{n} \cos \phi d \phi\right)_{t}=\left(k_{n}\right)_{t} \\
& =-\int_{\phi_{S}}^{\phi_{N}}\left\{\frac{\cos \phi}{a}\left[\frac{U(o)}{\cos \phi}\right]_{\phi} \Phi_{u v}(n)+\frac{1}{a} V_{\phi}(o) \Phi_{v v}(n)\right. \\
& \left.-\frac{\tan \phi}{a} V(o) \Phi_{u u}(n)+U_{p}(o) \Phi_{\omega u}(n)+V_{p}(o) \Phi_{\omega v}(n)\right\} \cos \phi d \phi \\
& +\int_{\phi_{S}}^{\phi_{N}} \sum_{\substack{m=-\infty \\
m \neq 0}}^{\infty}\left\{U(m)\left[\frac{1}{a \cos \phi} \Psi_{u u_{\lambda}}(m, n)+\frac{1}{a} \Psi_{v u_{\phi}}(m, n)-\frac{\tan \phi}{a} \Psi_{u v}(m, n)+\Psi_{\omega u_{p}}(m, n)\right]\right. \\
& \left.+V(m)\left[\frac{1}{a \cos \phi} \Psi_{u v_{\lambda}}(m, n)+\frac{1}{a} \Psi_{v v_{\phi}}(m, n)+\frac{\tan \phi}{a} \Psi_{u u}(m, n)+\Psi_{\omega v_{p}}(m, n)\right]\right\} \cos \phi d \phi \\
& -\int_{\phi_{S}}^{\phi_{N}} \frac{R}{p g} \Phi_{T \omega}(n) \cos \phi d \phi .
\end{aligned}
$$

Terms on the right denote (B5) contributions by wavezonal interactions, (B6) contributions by wave-wave interactions that are the components of barotropic energy interactions, and (B7) contributions from the conversion of eddy kinetic energy to the eddy available potential energy that is the baroclinic component of energy exchanges. The terms involving boundary fluxes are omitted.

Symbols $\Phi_{u v}$ and $\Psi_{u v}$ are defined by

$$
\begin{aligned}
\Phi_{u v}(n) & =U(n) V(-n)+U(-n) V(n) \\
\Psi_{u v}(m, n) & =U(n-m) V(-n)+U(-n-m) V(n) .
\end{aligned}
$$

It should be noted that although we have used summation limits on $m$ from $-\infty$ to $+\infty$ in the preceding expressions, we only carry our summation for the first 15 wavenumbers.

\section{REFERENCES}

Beljaars, A., and M. Miller, 1990: A note concerning the evaporation from the tropical oceans: Sensitivity of the ECMWF Model to the transfer coefficient of moisture at low wind speed. ECMWF Research Department Tech. Memo. 170, ECMWF, Reading, United Kingdom, 19 pp.
Businger, J. A., and J. C. Wyngard, 1971: Flux profile relationship in the atmospheric surface layer. J. Atmos. Sci., 28, 181-189.

Cocke, S., 1998: Case study of Erin using the FSU nested regional spectral model. Mon. Wea. Rev., 126, 1337-1346.

Colle, B. A., and C. F. Mass, 1995: The structure and evolution of cold surges east of the Rocky Mountains. Mon. Wea. Rev., 123, 2577-2610.

Harshvardan, and T. G. Corsetti, 1984: Longwave Parameterization for the UCLA/GLAS GCM. NASA Tech. Memo. 86072. [Available from NASA/Goddard Space Flight Center, Greenbelt, MD 20771.]

Kalnay, E., and Coauthors, 1996: The NCEP/NCAR 40-Year Reanalysis Project. Bull. Amer. Meteor. Soc., 77, 437-471.

Kanamitsu, M., 1975: On Numerical Weather Prediction over a Tropical Belt. Rep. 75-1, 282 pp. [Available from Dept. of Meteorology, The Florida State University, Tallahassee, FL 32306.]

- T. N. Krishnamurti, and C. Depradine, 1972: On scale interactions in the Tropics during northern summer. J. Atmos. Sci., 29, 698-706.

_, K. Tada, K. Kudo, N. Sako, and S. Isa, 1983: Description of the JMA Operational Spectral Model. J. Meteor. Soc. Japan, 61, 812-828.

Krishnamurti, T. N., 1980: Large scale features of the tropical atmosphere. Meteorology over the Tropical Oceans, D. B. Shaw, Ed., Royal Meteorology Society, 31-56.

— S. Low-Nam, and R. Pasch, 1983: Cumulus parameterization and rainfall rates, Part II. Mon. Wea. Rev., 111, 815-828.

, J. Xue, H. S. Bedi, K. Ingles, and D. Oosterhof, 1991: Physical initialization for numerical weather prediction over the Tropics. Tellus, 43A, 53-81. 
Lacis, A. A., and J. E. Hansen, 1974: A parameterization of the absorption of solar radiation in the earth's atmosphere. J. Atmos. Sci., 31, 118-133.

Lichtenstein, E., 1989: Some influences of the Andes Cordillera on the synoptic scale circulation. Extended Abstracts, Third Int. Conf. on Southern Hemisphere Meteorology and Oceanography, Buenos Aires, Argentina, Amer. Meteor. Soc., 146-148.

Louis, J. F., 1979: A parametric model of vertical eddy fluxes in the atmosphere. Bound.-Layer Meteor., 17, 187-202.

Marengo, J., A. Cornejo, P. Satyamurty, C. Nobre, and B. Sea, 1997a: Cold surges in the tropical and extratropical South America. The Strong Event in June 1994. Mon. Wea. Rev., 125, 2759-2786.

_ C. Nobre, and A. Culf, 1997b: Climatic impacts of "Friagens" in forested and deforested areas of the Amazon Basin. J. Appl. Meteor., 36, 1553-1566.
Saltzman, B., 1957: Equations governing the energetics of the large scales of atmospheric turbulence in the domain of wavenumber. J. Meteor., 14, 513-523.

_ 1970 : Large scale atmospheric energetics in the wavenumber domain. Rev. Geophys., 8, 289-302.

Schultz, D. M., E. D. Bracken, and L. F. Bosart, 1998: Planetary and synoptic-scale signatures associated with Central American cold surges. Mon. Wea. Rev., 126, 5-27.

Tiedke, M., 1984: The sensitivity of the time-mean large-scale flow to cumulus convection in the ECMWF model. Workshop on Convection in Large-Scale Numerical Models, ECMWF, 297-316.

Wallace, J. M., S. Tibaldi, and A. J. Simmons, 1983: Reduction of systematic forecast errors in the ECMWF model through the introduction of envelope orography. Quart. J. Roy. Meteor. Soc., 109, 683-718. 